\title{
Comparative chloroplast genome analysis of Impatiens species (Balsaminaceae) in the karst area of China: insights into genome evolution and phylogenomic implications
}

Chao Luo ${ }^{1,2}$, Wulue Huang ${ }^{1}$, Huayu Sun², Huseyin Yer², Xinyi Li', Yang Li', Bo Yan', Qiong Wang ${ }^{1}$, Yonghui Wen', Meijuan Huang ${ }^{1 *}$ and Haiquan Huang ${ }^{1 *}$

\begin{abstract}
Background: Impatiens L. is a genus of complex taxonomy that belongs to the family Balsaminaceae (Ericales) and contains approximately 1000 species. The genus is well known for its economic, medicinal, ornamental, and horticultural value. However, knowledge about its germplasm identification, molecular phylogeny, and chloroplast genomics is limited, and taxonomic uncertainties still exist due to overlapping morphological features and insufficient genomic resources.

Results: We sequenced the chloroplast genomes of six different species (Impatiens chlorosepala, Impatiens fanjingshanica, Impatiens guizhouensis, Impatiens linearisepala, Impatiens loulanensis, and Impatiens stenosepala) in the karst area of China and compared them with those of six previously published Balsaminaceae species. We contrasted genomic features and repeat sequences, assessed sequence divergence and constructed phylogenetic relationships. Except for those of I. alpicola, I. pritzelii and I. glandulifera, the complete chloroplast genomes ranging in size from 151,366 bp (I. alpicola) to 154,189 bp (Hydrocera triflora) encoded 115 distinct genes [81 protein-coding, 30 transfer RNA (tRNA), and 4 ribosomal RNA (rRNA) genes]. Moreover, the characteristics of the long repeat sequences and simple sequence repeats (SSRs) were determined. psbK-psbl, trnT-GGU-psbD, rpl36-rps8, rpoB-trnC-GCA, trnK-UUU-rps16, trnQ-UUG, trnP-UGG-psaJ, trnT-UGU-trnL-UAA, and ycf4-cemA were identified as divergence hotspot regions and thus might be suitable for species identification and phylogenetic studies. Additionally, the phylogenetic relationships based on Maximum likelihood (ML) and Bayesian inference (BI) of the whole chloroplast genomes showed that the chloroplast genome structure of I. guizhouensis represents the ancestral state of the Balsaminaceae family.
\end{abstract}

\footnotetext{
* Correspondence: xmhhq2001@163.com; haiquan|@163.com

${ }^{1}$ College of Landscape Architecture and Horticulture Sciences, Southwest Research Center for Engineering Technology of Landscape Architecture(State Forestry and Grassland Administration), Yunnan Engineering Research Center for Functional Flower Resources and Industrialization, Research and Development Center of Landscape Plants and Horticulture Flowers, Southwest Forestry University, Kunming, Yunnan 650224, China

Full list of author information is available at the end of the article
}

(c) The Author(s). 2021 Open Access This article is licensed under a Creative Commons Attribution 4.0 International License, which permits use, sharing, adaptation, distribution and reproduction in any medium or format, as long as you give appropriate credit to the original author(s) and the source, provide a link to the Creative Commons licence, and indicate if changes were made. The images or other third party material in this article are included in the article's Creative Commons licence, unless indicated otherwise in a credit line to the material. If material is not included in the article's Creative Commons licence and your intended use is not permitted by statutory regulation or exceeds the permitted use, you will need to obtain permission directly from the copyright holder. To view a copy of this licence, visit http://creativecommons.org/licenses/by/4.0/ The Creative Commons Public Domain Dedication waiver (http://creativecommons.org/publicdomain/zero/1.0/) applies to the data made available in this article, unless otherwise stated in a credit line to the data. 
Conclusion: Our study provided detailed information about nucleotide diversity hotspots and the types of repeats, which can be used to develop molecular markers applicable to Balsaminaceae species. We also reconstructed and analyzed the relationships of some Impatiens species and assessed their taxonomic statuses based on the complete chloroplast genomes. Together, the findings of the current study might provide valuable genomic resources for systematic evolution of the Balsaminaceae species.

Keywords: Impatiens, Balsaminaceae, Chloroplast genome, Comparative analysis, Phylogenetic relationship

\section{Background}

The nucleus, chloroplast $(\mathrm{cp})$, and mitochondrion are the three major organelles containing genomes within the cell [1]. Typically, the chloroplast genomes in angiosperms display a quadripartite circular double-helix structure with highly conserved sizes, structures, and gene sequences ranging from $115 \mathrm{~kb}$ to $165 \mathrm{~kb}$ in length [2]. The complete chloroplast genome's common feature is a typical tetrad structure consisting of a pair of inverted repeats (IRs) separated by the large and small single-copy regions (LSC and SSC regions, respectively). Generally, chloroplast genomes contain 110-113 genes, which are separated into three categories according to their functions [3]. The first is related to the expression of chloroplast genes such as transfer RNA (tRNA) genes, ribosomal RNA (rRNA) genes, and the three subunits associated with RNA polymerase synthesis. The second corresponds to photosynthesis-related genes, and the third to other biosynthetic genes and some genes of unknown function, such as $y c f 1, y c f 2$ and $y c f 15$ [4]. Compared to the nuclear and mitochondrial genomes, the chloroplast genome has a self-replication mechanism, relatively independent evolution, a small genome, low mutation rate and unique maternal inheritance [5]. Thus, the chloroplast genome can provide information for the evolutionary analysis, DNA barcoding, phylogenetic reconstruction and taxonomic identification of families and generas [6]. Furthermore, gene mutations, rearrangements, duplications and losses could be observed in the chloroplast genomes of angiosperm lineages [7]. Structural changes in genomes can be used to study taxonomic significance and phylogenetic relationships [8] and can supply information for developing genomic markers for complex, taxonomically challenging species [9]. Complete chloroplast genomes contain all genes for the reconstruction of evolutionary history and can provide more valuable and higher-quality information for evolutionary and phylogenetic analyses [10]. In addition, they can also reduce the sampling error inherent in studies of one or a few genes that may indicate critical evolutionary events [11].

Impatiens species, belonging to Balsaminaceae, form a taxonomically controversial and complex genus of flowering plants that have been widely used as medicinal, ornamental, and horticultural plants in North America,
Europe, and China [12]. Family Balsaminaceae consists of only two genera, namely, Impatiens and the monospecific sister genus Hydrocera (consisting of Hydrocera triflora; GenBank KF986530), with strong similarities in morphology and molecular biology [13]. Both are eudicot genera that belong to order Ericales and subclass Asteridae. The new classification of Impatiens based on morphological and molecular datasets divided it into two subgenera (Clavicarpa and Impatiens). Seven sections of the subgenus were further subdivided. Impatiens includes approximately 1000 species distributed from the tropics to the subtropics and extending from sea level to an altitude of $4000 \mathrm{~m}$ [14]. Tropical Africa, Madagascar, Sri Lanka, Himalayas, and Southeast Asia are the five biodiversity hotspots of Impatiens $[15,16]$.

The center of origin and diversification of Balsaminaceae is China, especially the karst area. Approximately 250 wild Impatiens species have been described from the Guizhou, Yunnan, and Guangxi areas, many of which are used as supplements for medicinal or health purposes. In ancient China, Impatiens plants were called 'zhijiahua' and were crushed into a mash and directly applied to the nails [17]. Pharmaceutical and chemical products of annual herbs can be used for the medical treatment of rheumatism, beriberi, bruises, pain, warts, snakebite, fingernail inflammation, and onychomycosis $[18,19]$. Additionally, previous research demonstrated that high levels of metals such as copper, zinc, chromium, and nickel could be accumulated by Impatiens species [20].

Due to the diversity of flowering and morphological characters in Impatiens, the phylogenetic relationships of Impatiens species remain uncertain [21]. Impatiens plants are characterized by zygomorphic flowers with substantial diversity and high levels of convergent evolution leading to variability in corolla color and morphology. The flowers are incredibly fragile, and most are coalesced and folded in dried specimens, making it difficult to separate and reconstruct different parts [22, 23]. Moreover, due to the semisucculent stems and many fleshy leaves, it is challenging to provide well-dried herbarium plant specimens [24]. Early research on Impatiens was primarily focused on a specific geographical area providing purely descriptive traditional taxonomy processing [25]. To date, the only global infrageneric 
molecular classification for Impatiens was performed based on plastid protein-coding genes matK, $r b c L$, and $\operatorname{trnK}$ and the intergenic regions $a t p B-r b c L$ and $\operatorname{trnL} L-\operatorname{trn} F$ $[26,27]$. Additionally, nuclear ribosomal internal transcribed spacer (ITS) and inter-simple sequence repeat (ISSR) markers have been used to assess the genetic diversity of populations and to understand the phylogenetic and evolutionary relationships among Impatiens species [28]. However, all published data were based on relatively short sequences from material with obvious regional characteristics, and some species with diversified morphology were subject to taxonomic controversy due to unresolved phylogenetic relationships; thus, further studies and clarification are required [29]. For this reason, the present study is based on complete chloroplast genome sequences, which yield much better resolution for the reconstructing phylogenies [30].

Twelve complete chloroplast genomes of Impatiens, including six newly sequenced chloroplast genomes (I. chlorosepala, I. fanjingshanica, I. guizhouensis, I. linearisepala, I. loulanensis and I. stenosepala), from the karst area of China were assembled by using Illumina sequencing technology and combined with previously published complete Balsaminaceae chloroplast genomes [31]. The present investigation is a novel attempt to reveal the phylogenetic position and taxonomic status of Impatiens based on the whole chloroplast genome. The aims of this study were to (i) conduct comprehensive research on the Impatiens chloroplast genome, generating information on basic genome structure, codon usage, repetitive structure characteristics, and IR expansion; (ii) identify hotspot regions, microsatellite types, and comparative genomic divergence; and (iii) reconstruct and analyze the relationships of Impatiens species and determine the taxonomic status of Impatiens based on the complete chloroplast genomes.

\section{Results}

\section{General features of Impatiens}

The genomic libraries generated $4.2-4.9 \mathrm{~Gb}$ of raw data, which were equivalent to $2.1-2.6 \mathrm{~Gb}$ of trimmed reads. After sequencing, cutting, and selecting reads, the 12 complete Balsaminaceae species chloroplast genomes ranged in size from 151,366 bp (I. alpicola) to 154,189 bp (H. triflora) (Table 1$)$. The newly sequenced Impatiens chloroplast genome maps were provided in Fig. 1 and Supplementary Figs. S1-S6 (I. chlorosepala, I. fanjingshanica, I. guizhouensis, I. linearisepala, I. loulanensis, and I. stenosepala). Similar to the pattern observed in other typical chloroplast genomes of angiosperms, the common feature of the complete chloroplast genomes consisted of four conjoined regions forming a circular molecular structure. The IRs were separated by LSC and SSC regions. In the chloroplast genomes of the family Balsaminaceae, the LSC region accounted for 54.47$55.04 \%$ of the total chloroplast genome, ranging from 82 , 247 bp (I. alpicola) to $84,865 \mathrm{bp}$ ( $H$. triflora); the SSC accounted for $11.37-11.73 \%$ of the total chloroplast

Table 1 Newly sequenced complete chloroplast genomes of Impatiens species

\begin{tabular}{|c|c|c|c|c|c|c|}
\hline & I. chlorosepala & I. fanjingshanica & I. guizhouensis & I. linearisepala & I. loulanensis & I. stenosepala \\
\hline Total length (bp) & 152,763 & 151,538 & 152,774 & 152,212 & 152,472 & 152,802 \\
\hline GC (\%) & 36.7 & 36.9 & 37 & 37 & 36.7 & 36.9 \\
\hline LSC region length (bp) & 83,740 & 82,542 & 83,572 & 83,508 & 83,460 & 83,626 \\
\hline GC (\%) & 34.3 & 34.6 & 34.8 & 34.8 & 34.4 & 34.5 \\
\hline SSC region length (bp) & 17,477 & 17,547 & 17,662 & 17,309 & 17,541 & 17,739 \\
\hline GC (\%) & 29.5 & 29.4 & 29.9 & 30 & 29.6 & 29.8 \\
\hline IR region length (bp) & 25,773 & 25,726 & 25,772 & 25,699 & 25,737 & 25,720 \\
\hline GC (\%) & 43.1 & 43.1 & 43 & 43 & 43 & 43.2 \\
\hline CDS length (bp) & 79,562 & 79,689 & 79,941 & 79,533 & 79,650 & 79,581 \\
\hline GC (\%) & 37.2 & 37.2 & 37.4 & 37.3 & 37.1 & 37.2 \\
\hline rRNA length (bp) & 9048 & 9048 & 9046 & 9048 & 9048 & 9048 \\
\hline GC (\%) & 55.1 & 55.1 & 55.1 & 55.2 & 55.1 & 55 \\
\hline tRNA length (bp) & 2876 & 2872 & 2872 & 2872 & 2872 & 2884 \\
\hline GC (\%) & 52.4 & 52.6 & 52.7 & 52.5 & 52.6 & 52.6 \\
\hline Total genes & 115 & 115 & 115 & 115 & 115 & 115 \\
\hline CDSs & 81 & 81 & 81 & 81 & 81 & 81 \\
\hline tRNAs & 30 & 30 & 30 & 30 & 30 & 30 \\
\hline rRNAs & 4 & 4 & 4 & 4 & 4 & 4 \\
\hline
\end{tabular}




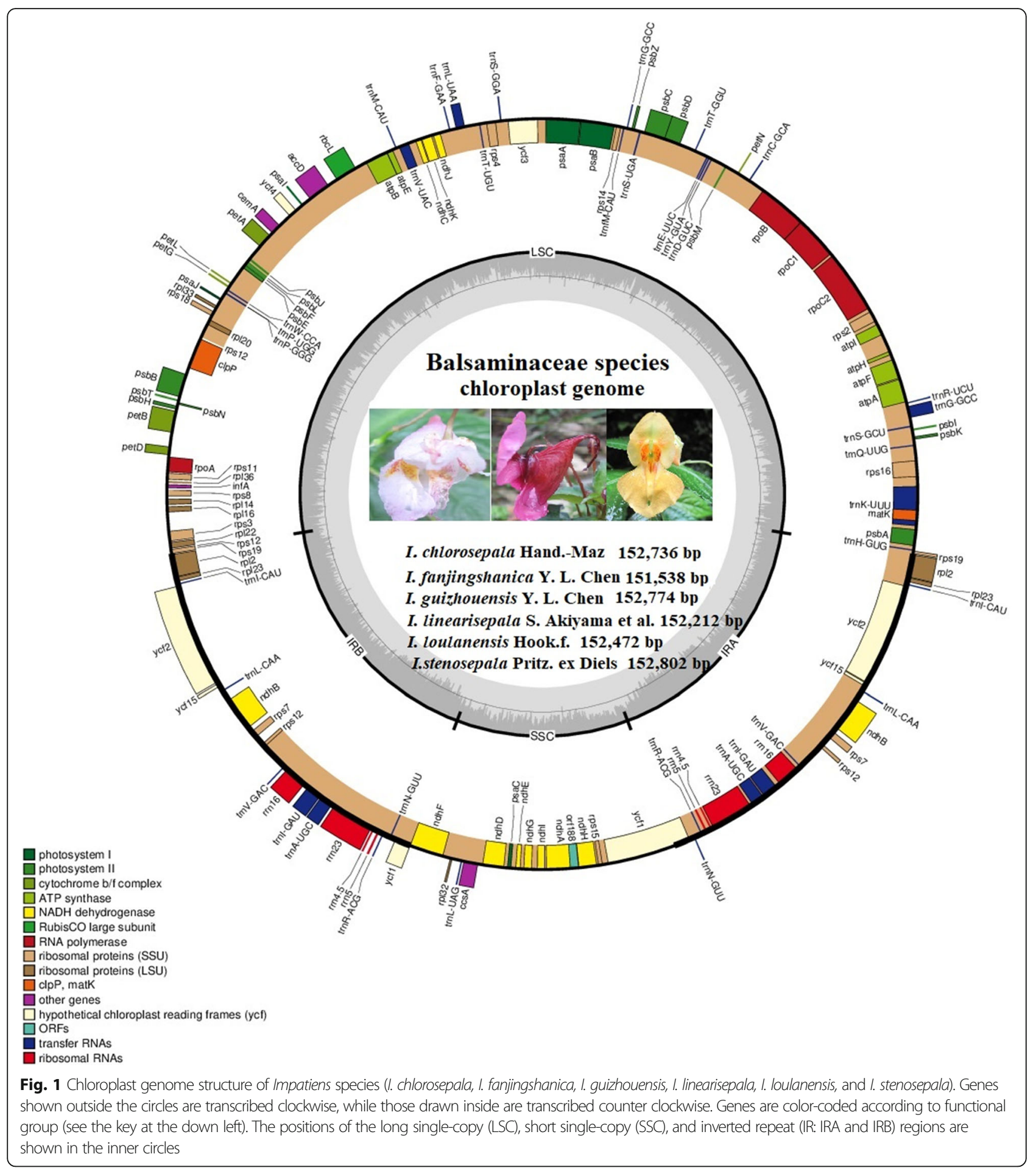

genome, ranging from $17,309 \mathrm{bp}$ (I. linearisepala) to $18,080 \mathrm{bp}$ ( $H$. triflora); and the IR accounted for $16.62-16.98 \%$ of the total chloroplast genome, ranging from 25,622 bp (H. triflora) to 25,773 bp (I. chlorosepala). In the newly sequenced chloroplast genomes of genus Impatiens, the LSC region accounted for $54.47-54.86 \%$ of the total chloroplast genome, ranging from $82,542 \mathrm{bp}$ (I. fanjingshanica) to $83,508 \mathrm{bp}$ (I. linearisepala); the SSC accounted for $53.58-58.27 \%$ of the total chloroplast genome, ranging from $17,309 \mathrm{bp}$ (I. linearisepala) to $17,547 \mathrm{bp}$ (I. fanjingshanica); and the IR accounted for $16.83-16.98 \%$ of the total chloroplast genome, ranging from $25,720 \mathrm{bp}$ (I. stenosepala) to $25,773 \mathrm{bp}$ (I. chlorosepala). 
Similar to most angiosperm chloroplast genomes, those of the Balsaminaceae species (except for I. alpicola, I. pritzelii, and I. glandulifera) encoded 115 distinct genes, including 81 protein-coding, 30 tRNA, and 4 rRNA genes (Supplementary Table S2). However, the trnG-UCC gene was annotated as a pseudogene in $H$. triflora compared to the other Impatiens species. The genes psbN, trnK-UUU, trnL-UAA, trnP-GGG, ycf15 and trnfM-CAU were missing due to incorrect annotation in I. glandulifera. The pseudogene orf188 was missing in $I$. alpicola and $I$. pritzelii. Thirteen genes (ccsA, nahA, $n d h D-I$, orf188, psaC, rpl32, rps15, and trnL-UAG) were not annotated in I. alpicola. The genes were classified into three groups based on their functions: (1) transcription and RNA genes, including four transcription genes (rpoA, rрoв, rрoC1*, and $r p o C 2$ ), 20 ribosomal proteins, 4 ribosomal RNAs (rrn4.5, rrn5, rrn16, and rrn23), and 30 transfer RNAs; (2) photosynthesis-related genes (in the Rubisco, ATP synthase, Photosystem I, Cytochrome b/f complex, Photosystem II, Cytochrome c synthesis, and NADPH dehydrogenase groups); and (3) other genes, including four genes $(\operatorname{mat} K, \operatorname{cem} A, \operatorname{acc} D$, and $c l p P$ ) with known functions and three conserved reading frame genes $(y c f 1, y c f 2$, and $y c f 15)$ encoding proteins (Table 2 and Supplementary Table S1).

A total of 16 chloroplast genes had introns in the Impatiens species. Introns were missing in one of these genes in I. piufanensis (rps16) and H. triflora (trnG-GCC tRNA gene), respectively. The 16 genes could be classified into two groups according to their introns: group I included 14 genes with a single intron, and group II included two genes $(y c f 3$ and $c l p P)$ with two introns. Eleven of these intron-containing genes $(c l p P, y c f 3$, truv$U A C, \operatorname{rps} 12, \operatorname{trnK-UUU,~rpoC1,~petB,~trnL-UAA,~atpF,~}$ trnG-GCC, and rps16) were in the LSC region, four genes ( $t R N A-G A U, \operatorname{trn} A-U G C, n d h B$, and $r p l 2$ ) were in the IR region and only one gene $(n d h A)$ was in the SSC

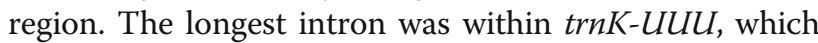
ranged from $2488 \mathrm{bp}$ (I. loulanensis) to $2548 \mathrm{bp}$ (I. guizhouensis), and the exon of rpoC1 was the longest. Moreover, rps12 is a trans-splicing gene that was divided into $5^{\prime}$-rps12 in the LSC region and $3^{\prime}$-rps 12 in the IR region (Table 2 and Supplementary Table S3).

\section{Differences in genome size}

Among the 12 Balsaminaceae species, I. alpicola had the smallest chloroplast genome (151,366 bp), and H. triflora

Table 2 List of genes in the chloroplast genomes of the Impatiens species

\begin{tabular}{|c|c|c|}
\hline Function of Genes & Group of Genes & Gene Names \\
\hline \multirow{8}{*}{$\begin{array}{l}\text { Photosynthesis-related } \\
\text { genes }\end{array}$} & Rubisco & $r b c L$ \\
\hline & Photosystem I & psaA, psaB, psaC, psal, psaJ \\
\hline & $\begin{array}{l}\text { Assembly and stability of } \\
\text { Photosystem I }\end{array}$ & $y c f 3^{* *}, y c f 4$ \\
\hline & Photosystem II & $p s b A, p s b B, p s b C, p s b D, p s b E, p s b F, p s b H, p s b l, p s b J, p s b K, p s b L, p s b M, p s b N, p s b T, p s b Z$, \\
\hline & ATP synthase & atpA, atpB, atpE, atpF*, atpH, atpl \\
\hline & $\begin{array}{l}\text { Cytochrome b/f } \\
\text { complex }\end{array}$ & pet $A$, petB*, petD, petG, petL, petN \\
\hline & Cytochrome c synthesis & $\operatorname{ccs} A$ \\
\hline & NADPH dehydrogenase & $n d h A^{*}, n d h B^{*}(2), n d h C, n d h D, n d h E, n d h F, n d h G n d h H, n d h l, n d h J, n d h K$ \\
\hline \multirow{2}{*}{$\begin{array}{l}\text { Transcription- and } \\
\text { translation-related genes }\end{array}$} & Transcription & $r p o A, r p o B, r p o C 1^{*}, r p o C 2$ \\
\hline & Ribosomal proteins & $\begin{array}{l}r p 12^{*}(2), r p / 14, r p / 16, r p 120, r p 122, r p / 23(2), r p / 33, r p 136, r p s 2, r p s 3, r p s 4, r p s 7(2), r p s 8, r p s 11, \\
r p s 12^{*}(2), r p s 14, r p s 15, r p s 16 *, r p s 18, r p s 19(2)\end{array}$ \\
\hline \multirow[t]{2}{*}{ RNA genes } & Ribosomal RNA & $r r n 4.5, r r n 5, r r n 16, r r n 23$ \\
\hline & Transfer RNA & $\begin{array}{l}\operatorname{trn} A-U G C(2), \operatorname{trn} C-G C A, \operatorname{trn} D-G U C, \operatorname{trn} E-U U C, \operatorname{trn} F-G A A, \operatorname{trn} f M-C A U, \operatorname{trn} G-G C C^{*}, \operatorname{trn} G-U C C, \operatorname{trn} H- \\
G U G, \operatorname{trn} l-C A U^{*}(2), \operatorname{trn}-G A \cup(2), \operatorname{trn} K-U U U^{*}, \operatorname{trn} L-C A A(2), \operatorname{trn} L-U A G, \operatorname{trn} L-U A A^{*}, \operatorname{trn} M-C A U, \operatorname{trn} N- \\
G \cup U(2), \operatorname{trn} P-U G G, \operatorname{trn} Q-U U G, \operatorname{trn} R-A C G(2), \operatorname{trn} R-U C U, \operatorname{trn} S-G C U, \operatorname{trn} S-G G A, \operatorname{trn} S-U G A, \operatorname{trn} T-G G U, \\
\operatorname{trn} T-U G U, \operatorname{trn} V-G A C(2), \operatorname{trn} V-U A C^{*}, \operatorname{trn} W-C C A, \operatorname{trn} Y-G U A\end{array}$ \\
\hline \multirow[t]{4}{*}{ Other genes } & RNA processing & matk \\
\hline & Carbon metabolism & cemA \\
\hline & Fatty acid synthesis & $a c c D$ \\
\hline & Proteolysis & $c l p P^{* *}$ \\
\hline $\begin{array}{l}\text { Genes of unknown } \\
\text { function }\end{array}$ & $\begin{array}{l}\text { Conserved reading } \\
\text { frames }\end{array}$ & $y c f 1, y c f 2(2), y c f 15(2)$ \\
\hline
\end{tabular}

(2) indicates that $\mathrm{m}$ (the number of repeat units) is 2 ; ${ }^{*}$ Gene contains one intron; ${ }^{*}$ Gene contains two introns 
had the largest chloroplast genome (154,189 bp). Among the six newly sequenced species, I. stenosepala had the largest chloroplast genome (152,802 bp), whereas I. fanjingshanica had the smallest (151,538 bp). Except for $I$. stenosepala and I. fanjingshanica, the genome sizes of Impatiens species varied between 152,212 bp and 152, 774 bp (Table 1). Except for I. fanjingshanica, the genome sizes of other Balsaminaceae species were larger than 152,000 bp (Supplementary Table S1). In the 12 Balsaminaceae species, the lengths of the protein-coding genes ranged from 79,533 bp (I. linearisepala) to 80,952 bp ( $H$. triflora), and the length of the rRNAs totaled 9048 bp except in I. guizhouensis, I. glandulifera, and $H$. triflora, for which the lengths were $9046 \mathrm{bp}, 9050 \mathrm{bp}$, and $9046 \mathrm{bp}$, respectively. The length of the tRNA genes added 2872 bp except in I. chlorosepala, I. stenosepala, I. glandulifera, and H. triflora, whose lengths added 2876 bp, $2884 \mathrm{bp}, 2419 \mathrm{bp}$, and $2815 \mathrm{bp}$, respectively (Supplementary Table S1). The overall guanine-cytosine (GC) contents in the whole chloroplast genomes and the LSC, SSC, and IR regions were very similar among the species. The total GC content in the Balsaminaceae species ranged from 36.7 to $37 \%$, with I. chlorosepala and I. loulanensis having the lowest GC content and I. guizhouensis and I. linearisepala, the highest (Table 1). The average GC contents of the LSC, SSC, and IR regions were $34.56,29.7$, and $43.0 \%$, respectively (Table 1 and Supplementary Table S1).

\section{Codon usage}

The most commonly used transcription initiation codon was ATG. The termination codons were UGA, UAG, and UAA. For the Balsaminaceae species (Supplementary Table S4), we found that the most abundant amino acid (AA) was leucine and that UUA had the highest relative synonymous codon usage (RSCU) value at approximately 1.92 . Tryptophan was the lowest-frequency AA in the Balsaminaceae species. All AAs, except for methionine and tryptophan, had more than one synonymous codon. Among the AAs, leucine, arginine, and serine had six codons. The RSCU results indicated a bias toward $\mathrm{A}$ or $\mathrm{T}$ rather than $\mathrm{G}$ or $\mathrm{C}$ at the third codon position in the 12 Balsaminaceae species. I. glandulifera uses 30 different codons, which is lower than the expected usage at equilibrium ( $\mathrm{RSCU}<1) . H$. triflora used 36 codons more frequently than the rest of the Impatiens species, showing codon usage bias for 34 codons.

\section{Repeat structure analysis}

Among the 12 Balsaminaceae species, 234 long repeats of four types (forward, complement, reverse, and palindromic) were identified using REPuter (Supplementary Table S5). The most common repeat types were forward and palindromic repeats. Complement repeats were identified only in I. guizhouensis and I. pritzelii; reverse repeats were found in I. chlorosepala, I. fanjingshanica, I. linearisepala, I. pritzelii, and I. hawkeri. Most copy lengths were in the range of $30-40 \mathrm{bp}$ (Fig. 2B). The species with the most significant number of repeats were $I$. chlorosepala, with 25 repeats, comprising 14 forward, 9 palindromic, and 2 reverse repeats. I. linearisepala, which had the smallest number of repeats, had 5 forward, 7 palindromic, and 3 reverse repeats (Fig. 2A). The greatest numbers of forward, complement, and reverse repeats were found in I. chlorosepala (14), I. pritzelii (2), and I. linearisepala (3), respectively.

\section{Simple sequence repeat analysis}

Simple sequence repeats (SSRs), also called microsatellites, are widely used as molecular markers and play a significant role in plant identification and classification. The 51-109 SSRs examined for the Balsaminaceae species ranged in size from 10 to $20 \mathrm{bp}$. Six types of SSRs were found (Fig. 3A and Supplementary Table S6). Only $H$. triflora had hexanucleotide repeats, whereas I. loulanensis, I. stenosepala, and $H$. triflora had pentanucleotide repeats. The number of mononucleotide repeats ranged from 33 (H. triflora) to 82 (I. chlorosepala), followed by dinucleotides, ranging from 5 (I. hawkeri) to 13 (I. chlorosepala, I. fanjingshanica, and I. glandulifera) (Fig. 3BG). Therefore, mononucleotide and dinucleotide repeats may play a more significant role than other types of repeats in genetic variation.

Mononucleotide repeats were more abundant in the six newly sequenced chloroplast genomes, with $\mathrm{A} / \mathrm{T}$ repeats being the most highly represented repeats, whereas poly $\mathrm{C} / \mathrm{G}$ repeats were relatively rare. Poly $\mathrm{C} / \mathrm{G}$ repeats were found only in I. chlorosepala, I. fanjingshanica, I. guizhouensis, and I. loulanensis. Moreover, the number of mononucleotide repeats ranged from 24 (I. fanjingshanica and I. linearisepala) to 37 (I. loulanensis), with the number of $\mathrm{T}$ mononucleotide repeats ranging from 35 (I. linearisepala) to 48 (I. fanjingshanica) (Fig. 3B-G).

Among the dinucleotide repeats, the AT/TA motif was the most abundant. In the newly sequenced chloroplast genomes, SSR analysis showed that I. chlorosepala had the highest number of SSRs (109), while I. linearisepala had the lowest (74). Trinucleotide (ATT, GAA, TAA, TTA, TAT, ATA, and TTG) and tetranucleotide (AAAT, AATA, AATT, ATAA, TAAA, TATT, TTCA, TTTA, GTTT, and TTCT) motifs were identified. Among the newly sequenced chloroplast genomes, pentanucleotide (AAAAG and CAAAA) repeats were found only in those of I. loulanensis and I. stenosepala.

\section{Comparison of genome structures}

The structure and size of the chloroplast genome can change based on the evolutionary and genetic 


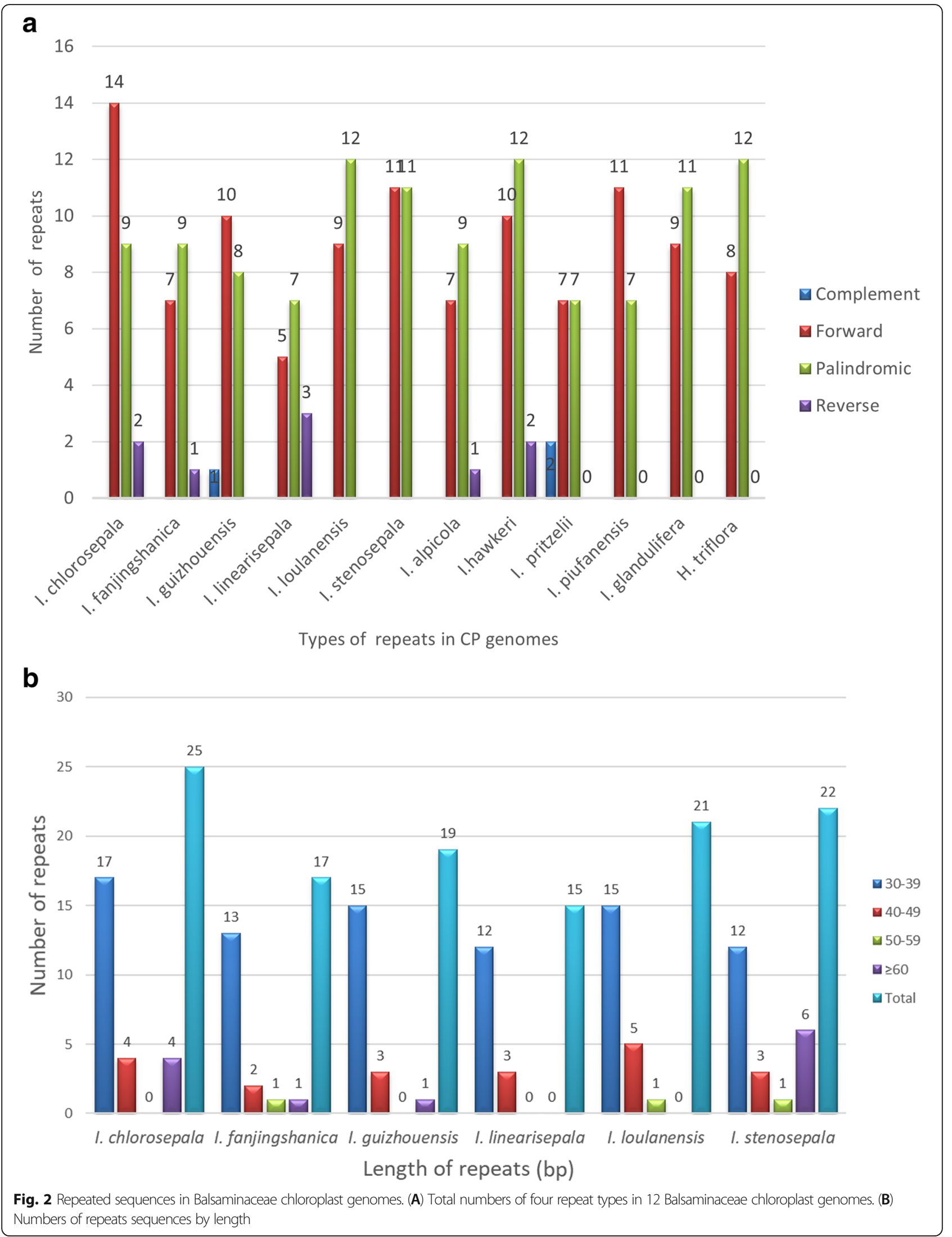




\section{a $_{16}$}

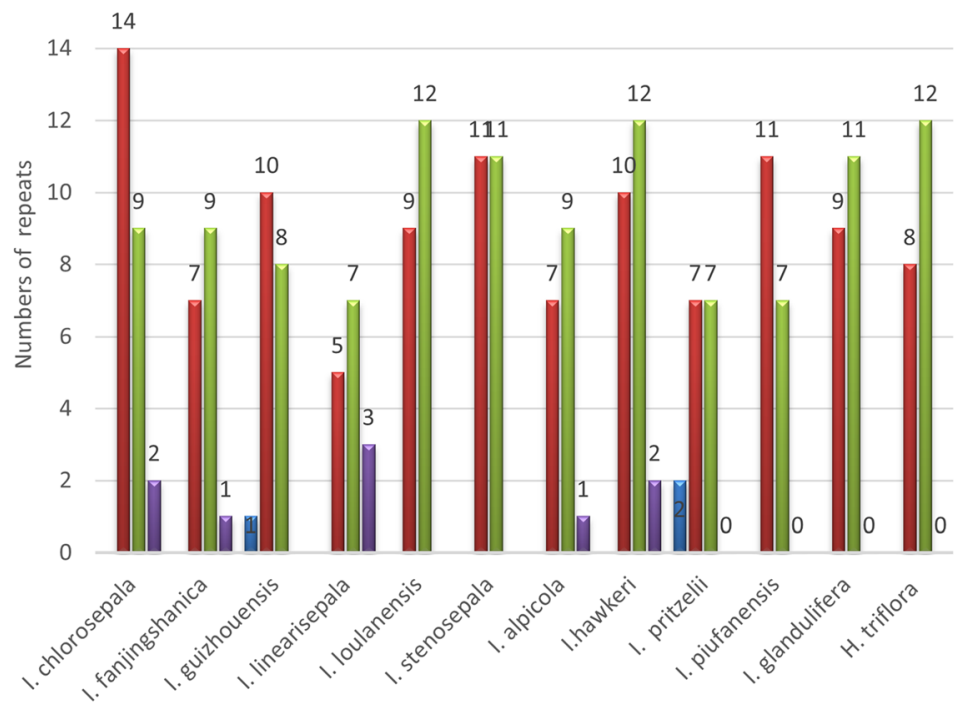

\Complement

Forward

$\square$ Palindromic

Reverse

Types of repeats in CP genomes

b

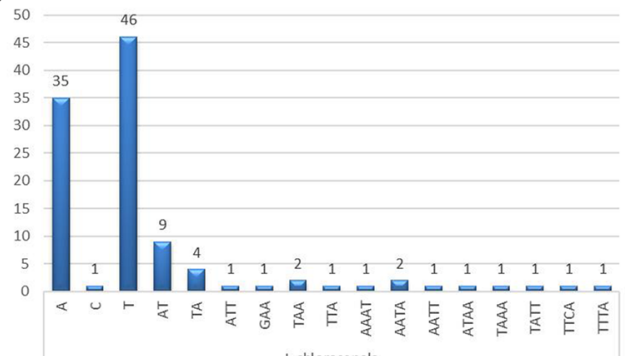

d

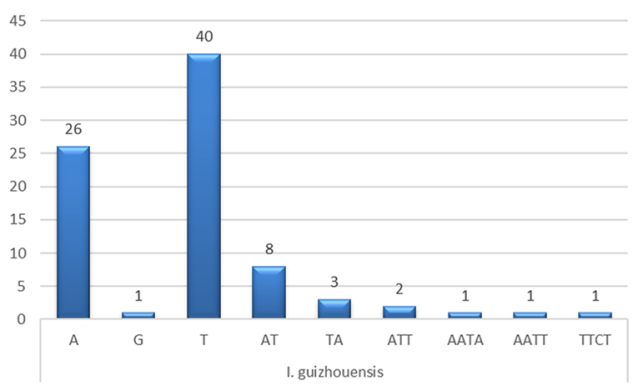

f

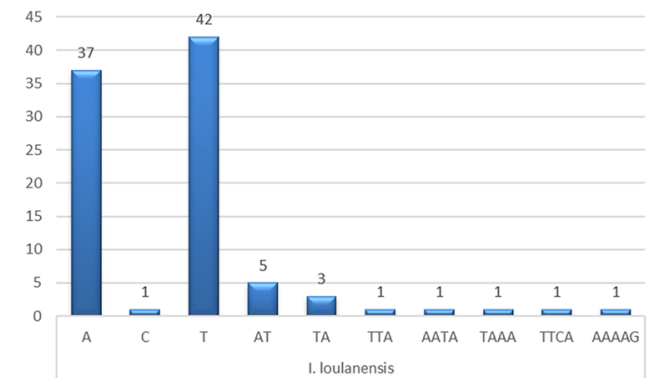

C

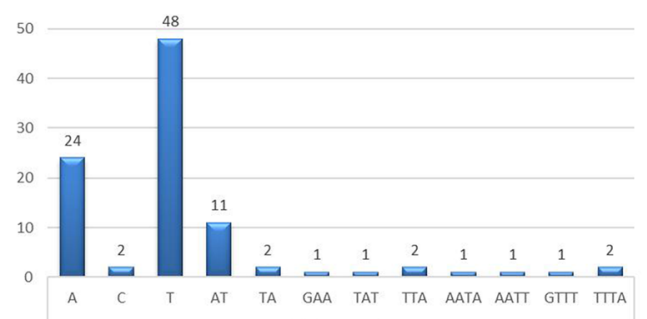

e

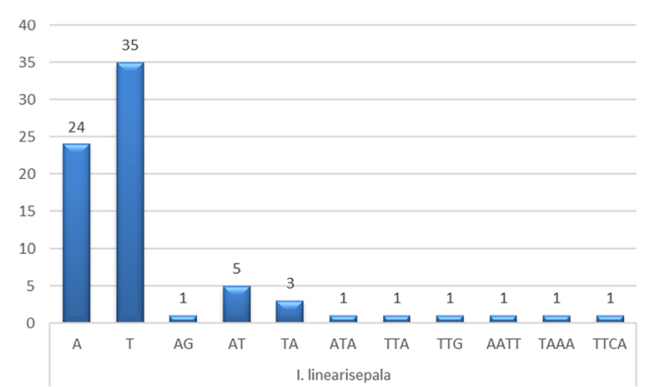

g

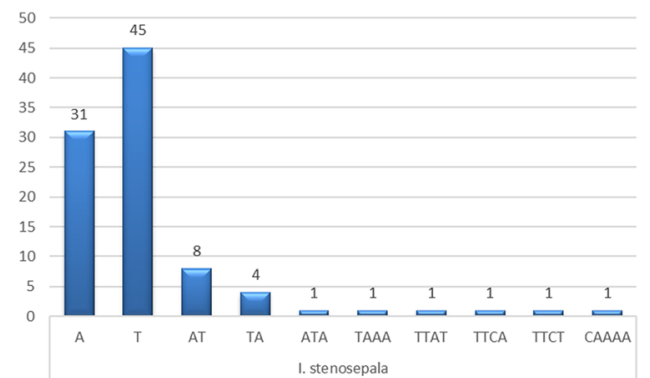

Fig. 3 SSR locus analysis of 12 Balsaminaceae chloroplast genomes. (A) Numbers of different SSR types detected in the 12 genomes. (B-G): Frequencies of identified SSR motifs in different repeat class types 


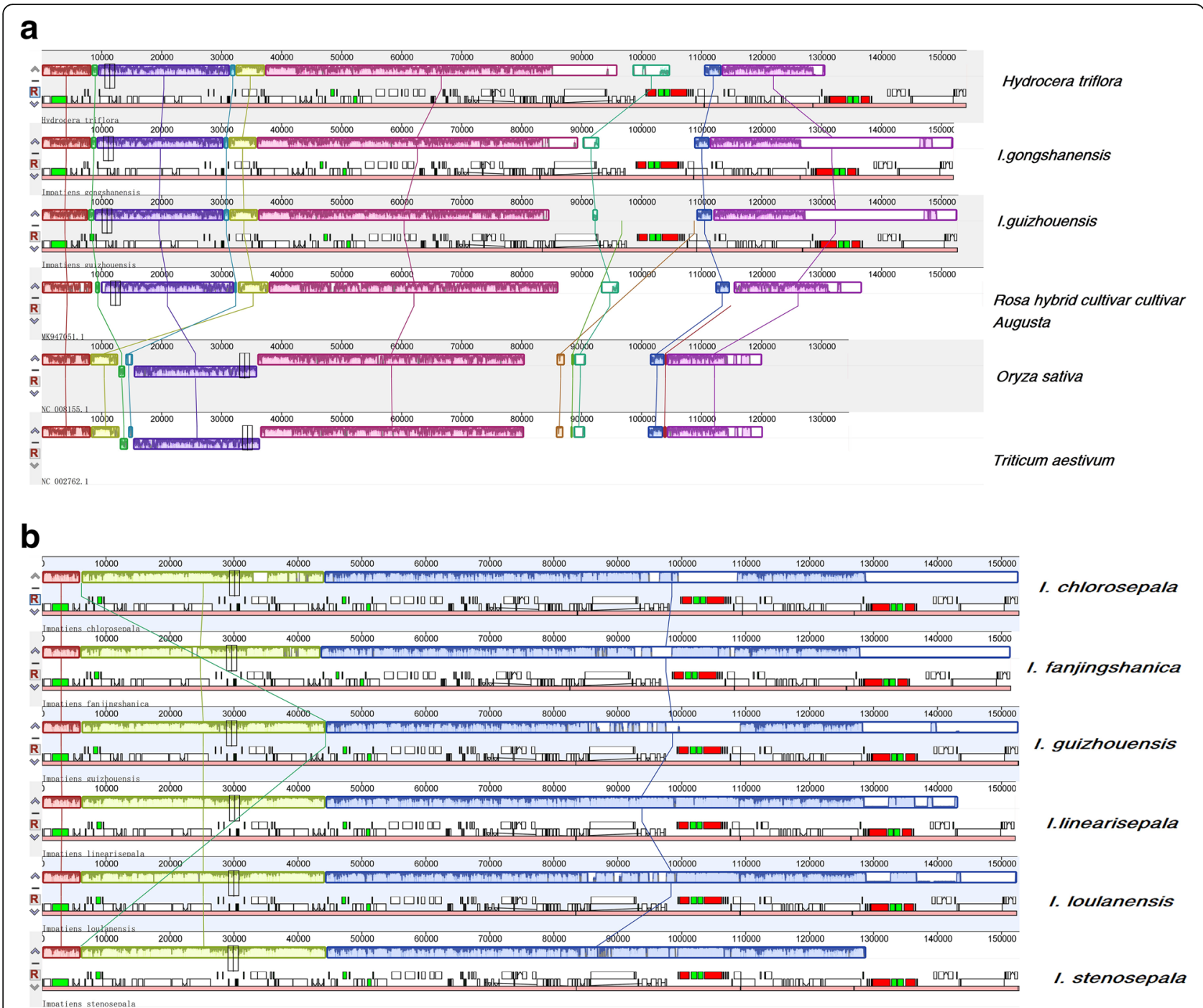

Fig. 4 Mauve alignment. (A) Two rearrangements concerning the dicot plastome with LSC and IRB intermolecular recombination. (B) Mauve alignment of six Balsaminaceae plastomes revealing no interspecific rearrangements

backgrounds. Collinearity detection was used to analyze and compare the chloroplast genomes. Mauve alignment of plastomes showed that the plastome structure of Impatiens was similar to that of the dicot Rosa (MK947051) (Fig. 4A). However, on the basis of a comparison with the monocots Triticum aestivum (NC002762) and Oryza sativa (NC008155), the monocot and dicot structures were derived from intermolecular recombination events (Fig. 4A). There were no interspecific or intraspecific rearrangements within the six species, which revealed that all genes (including rRNA, tRNA, and protein-coding genes) in the Balsaminaceae were conserved and arranged in the same order (Fig. 4B); this also applied to the optimal collinearity between Impatiens subgenera, as there were no gene rearrangements. Moreover, compared with the genome structure and gene sequence of $H$. triflora, those of the Impatiens subgenera were similar.

\section{Comparative analysis of genomic divergence and genome rearrangement}

A comparative analysis of the whole chloroplast genome between $H$. triflora and the other Impatiens species was conducted by using mVISTA software and DnaSP to detect hypervariable regions and construct sequence identity plots (Fig. 5A). The comparison showed that the numbers and sequences of genes in the IR regions were relatively conserved and less divergent than those in the LSC and SSC regions (Fig. 5B and C). Among the protein-coding genes, matK, psbK, pet $N$, psbM, atpE, rbcL, accD, psaL, rpl16, rpoB, $n d h B, n d h F, y c f 1$, and $n d h H$ contained highly divergent regions (Fig. 5A). For the intergenic regions, atpH-atpI, trnC-trnT, rps3-rps19, and ndhG-ndhA were 


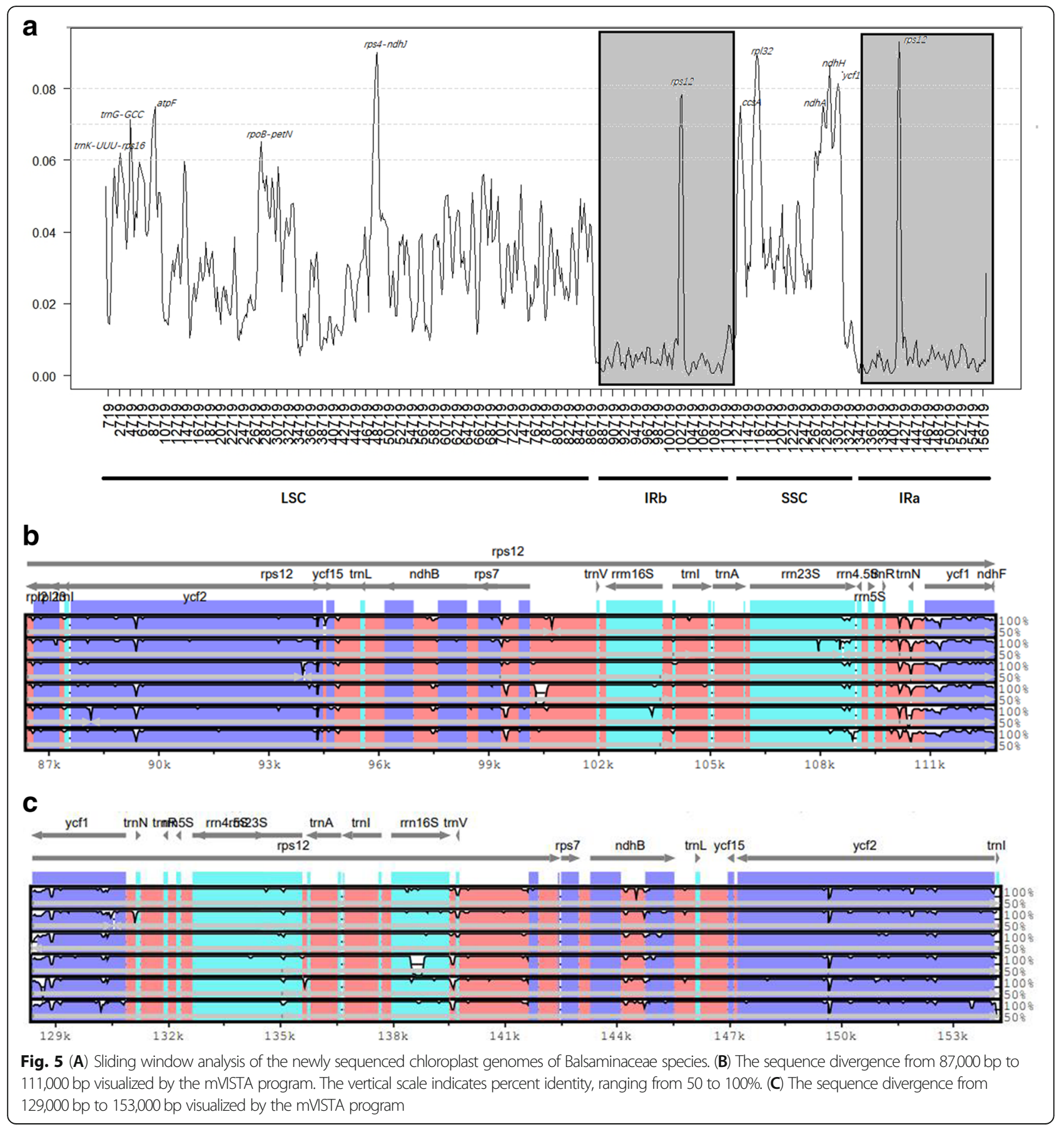

the most variable. In the LSC region, the $p s b K-p s b I$, atpI, and rps4-trnF genes showed some sequence divergence in I. piufanensis, I. glandlifera, and $H$. triflora. The three genes $n d h F, y c f 1$, and $n d h H$ were detected in the SSC region. rpl32-trnN showed the highest variation among the hypervariable regions, and the $y c f 1$ gene was the most divergent. Compared with those of $H$. triflora, the large copies of the trnl-trnN and trnA-trnL loci in the chloroplast genomes of I. fanjingshanica, I. guizhouensis, and I. loulanensis were absent.
Sequence divergence and mutational hotspots

We compared nucleotide diversity $(\pi)$ values in DnaSP 5.1 to determine the divergence hotspot regions in 12 Balsaminaceae species. This analysis indicated that the variation in the LSC and SSC regions was much higher than that in the IR regions (Fig. 6). The highest $\pi$ values were observed for $y c f 1(0.17)$ and trnG-GCC (0.13). Six mutational hotspots that exhibited markedly higher $\pi$ values $(>0.06)$ in the LSC and SSC regions were trnkUUU-rps16, trnG-GCC, atpH-atpL, rpoB-petN, rps4- 


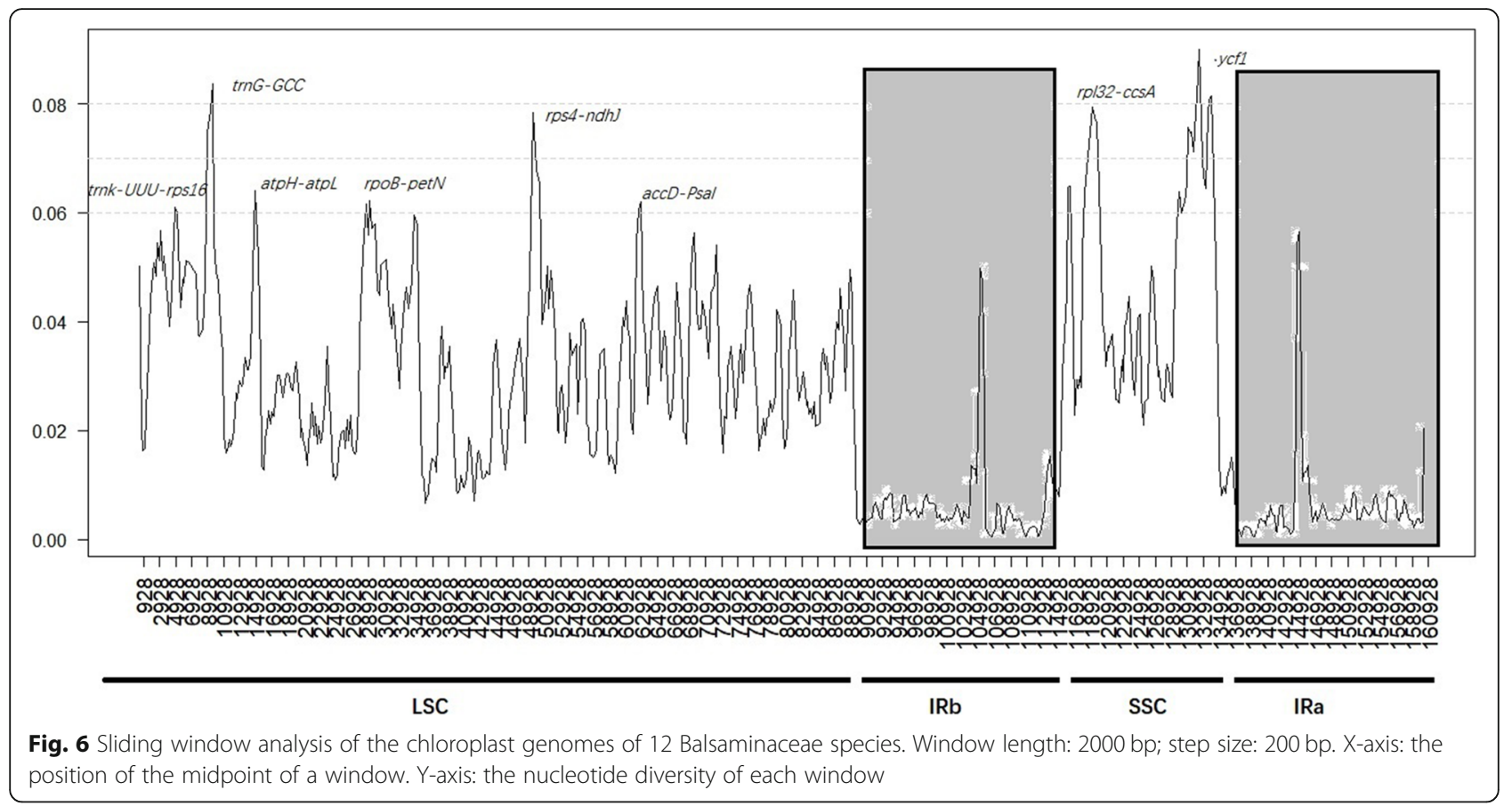

$n d h J$, and accD-psal, whereas in the SSC region, there were three hotspots ( $n d h F, r p l 32-c c s A$, and $y c f 1)$ with values above 0.06 . Similarly, we determined the average pairwise sequence divergence among newly sequenced Impatiens species. The $\pi$ values of these 140 regions ranged from $0.0 \%$ (rrn16) to $9.3 \%$ (rps12). The rps12 gene showed the highest average sequence divergence (0.93), followed by rpl32 (0.91) and rps4-ndhJ (0.90) (Fig. 6 and Supplementary Table S7). In contrast, the $\pi$ values of the six newly sequenced species were higher than those of the other 12 Balsaminaceae species. Therefore, these coding regions and noncoding genes may provide stronger signal for resolving the low-level phylogeny and phylogeography of species in Balsaminaceae.

\section{Contraction and expansion of inverted repeats}

Genome structure and the number and sequence of genes were highly conserved among the 12 Balsaminaceae species. However, the contraction and expansion of IR boundaries changed in terms of structure and size. In the 12 Balsaminaceae species, we localized $y c f 1$ to the IRA-LSC boundary, the IRs of I. chlorosepala were the longest (25,773 bp), and those of $H$. triflora were the shortest $(25,622 \mathrm{bp})$. The LSC-IRB junctions were embedded in the rps19 genes. The length of rps 19 in the LSC region varied from 0 to $246 \mathrm{bp}$. However, the overlap between rps 19 and the IRB region varied from 0 to $200 \mathrm{bp}$. The IRB-SSC junction was located adjacent to genes $y c f 1$ and $n d h F$. In all species except for I. linearisepala, this junction adjoined the end of $y c f 1$ from 0 to $1256 \mathrm{bp}$, and the distance between $y c f 1$ and the IRB-SSC junction in I. linearisepala was $204 \mathrm{bp}$. Overlap between the $n d h F$ and $y c f 1$ genes was detected in I. guizhouensis, I. linearisepala, and I. hawkeri, where $n d h F$ expanded into the IRB region by $18 \mathrm{bp}$, $176 \mathrm{bp}$, and $98 \mathrm{bp}$, respectively (Fig. 7).

In the other species, the distances between $n d h F$ and the IRB-SSC junction varied from 1 to $2000 \mathrm{bp}$. The SSC-IRA junction was located in the pseudogene $y c f 1$, which covered the IRA and SSC regions. The length of the pseudogene $y c f 1$ in the SSC region varied from 4356 to $4891 \mathrm{bp}$. However, the overlap between the pseudogene $y c f 1$ and the IRA region varied from 810 to $1254 \mathrm{bp}$. The IRB/SSC and SSC/ IRA regions were variable. The rps19-psbA coding region extended into the boundaries of the LSC/IRA regions in all species except I. piufanensis, I. glandulifera, and H. triflora, in which the rps19 gene was missing from the junction of the LSC/IRB regions. However, the length of rps19 in the LSC region varied from 0 to $136 \mathrm{bp}$. In contrast, the lengths of rps19 in the IRB regions of I. guizhouensis and I. stenosepala were 31 and $137 \mathrm{bp}$, respectively. Among the six newly sequenced species, I. chlorosepala and I. linearisepala harbored the longest $(25,773 \mathrm{bp})$ and shortest $(25,699 \mathrm{bp})$ IR regions, respectively.

\section{Phylogenetic analyses within Balsaminaceae species}

We used Maximum likelihood (ML) and Bayesian inference (BI)-based phylogenetic trees to explore the taxonomic positions and evolutionary relationships of Balsaminaceae species based on the complete chloroplast genomes (Supplementary Table S8). According to the APG IV classification for the orders and families of flowering plants, we selected six families belonging to Ericales, namely, Ebenaceae, Styracaceae, Actinidiaceae, Theaceae, Primulaceae, and Balsaminaceae. 


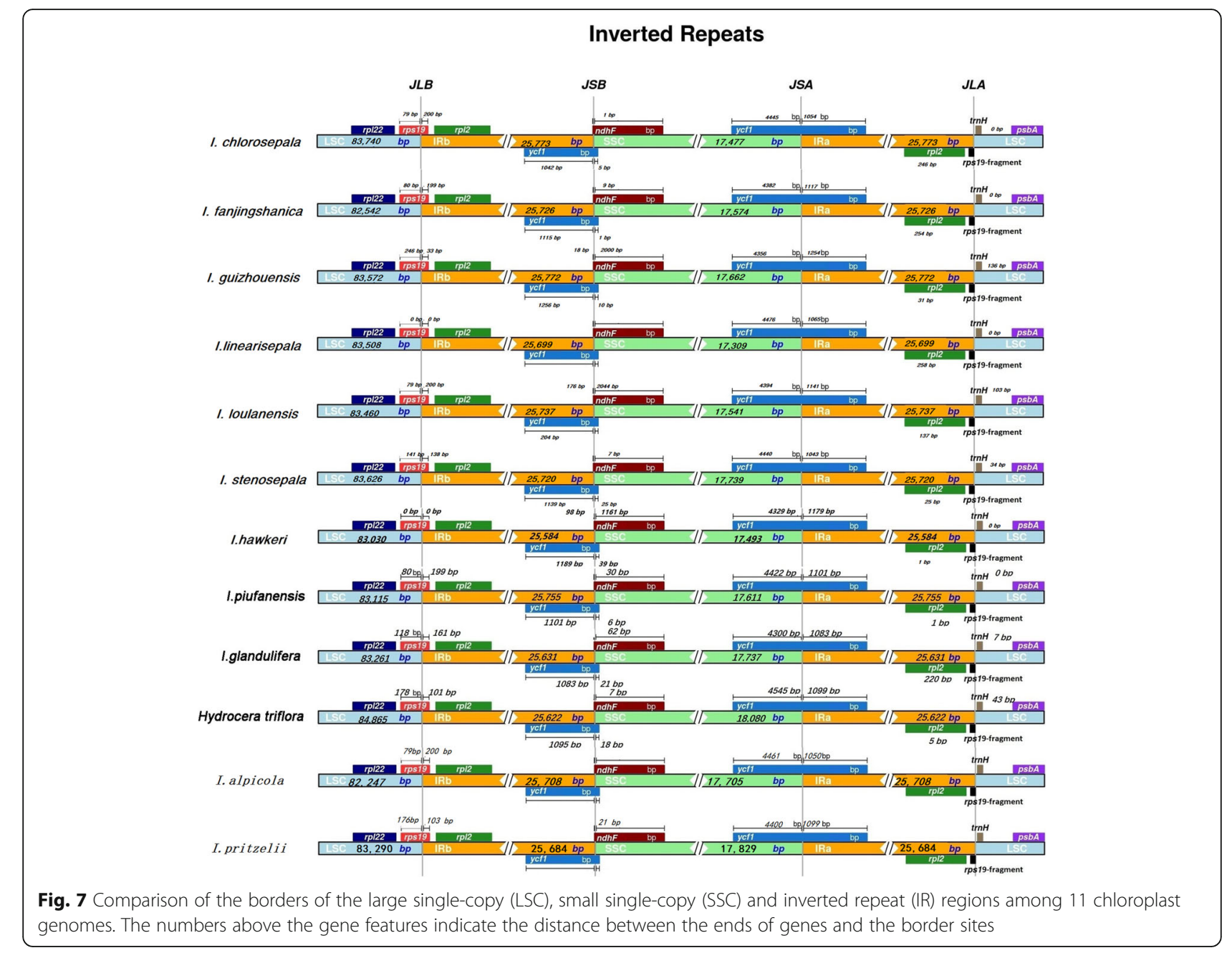

Species from families Saxifragaceae and Rosaceae were selected as outgroups due to their closer distances to Ericales as well as ornamental and horticultural value. The 12 Balsaminaceae species included those with published plastid genomes (I. piufanensis, I. glandlifera, I. hawkeri, I. alpicola, I. pritzelii, and $H$. triflora) and six newly sequenced species ( $I$. chlorosepala, I. fanjingshanica, I. guizhouensis, I. linearisepala, I. loulanensis, and I. stenosepala).

The ML and BI reconstructed topologies were highly supported, and the five selected families (Primulaceae, Actinidiaceae, Theaceae, Ebenaceae, and Styracaceae) other than Balsaminaceae formed five monophyletic groups. The genera Hartia and Stewartia of family Ebenaceae were clustered into a clade, whereas Theoideae consisted of Actinidia and Rhododendron. Only three nodes (Primulaceae, Theaceae, and Ebenaceae) had bootstrap values under $90 \%$ in the ML tree (Fig. 8). The remaining nodes had support values of $100 \%$. Only two nodes (Primulaceae and Actinidiaceae) had posterior probability values under 0.9 in the $\mathrm{BI}$ tree. The remaining nodes had support values of 1 (Fig. 8).
Phylogenetic reconstruction using ML and BI (Fig. 8 and Additional File 2: Fig. S5) divided all Balsaminaceae species into four main lineages (I to IV) with maximal support $(\mathrm{PP}=1, \mathrm{BS}=100 \%)$. Lineage I contained five Impatiens species (I. chlorosepala, I. hawkeri, I. alpicola, I. piufanensis, and I. fanjingshanica). Within this lineage $I$. fanjingshanica and I. piufanensis were sister species. Lineage II contained I. stenosepala, I. linearisepala, I. loulanensis and I. glandulifera. Within this lineage, I. glandlifera and I. loulanensis were sister to I. linearisepala and I. stenosepala with the species displaying the most similar morphological characteristics clustering together. Lineage III had only two species (I. guizhouensis and $I$. pritzelii). Lineage IV contained $H$. triflora.

\section{Discussion}

\section{Chloroplast genome structure}

Twelve complete chloroplast genomes of Balsaminaceae were compared and found to include 102-115 genes, including 69-81 protein-coding genes, 25-30 tRNAs, and 4 rRNAs. The chloroplast genomes of Balsaminaceae 


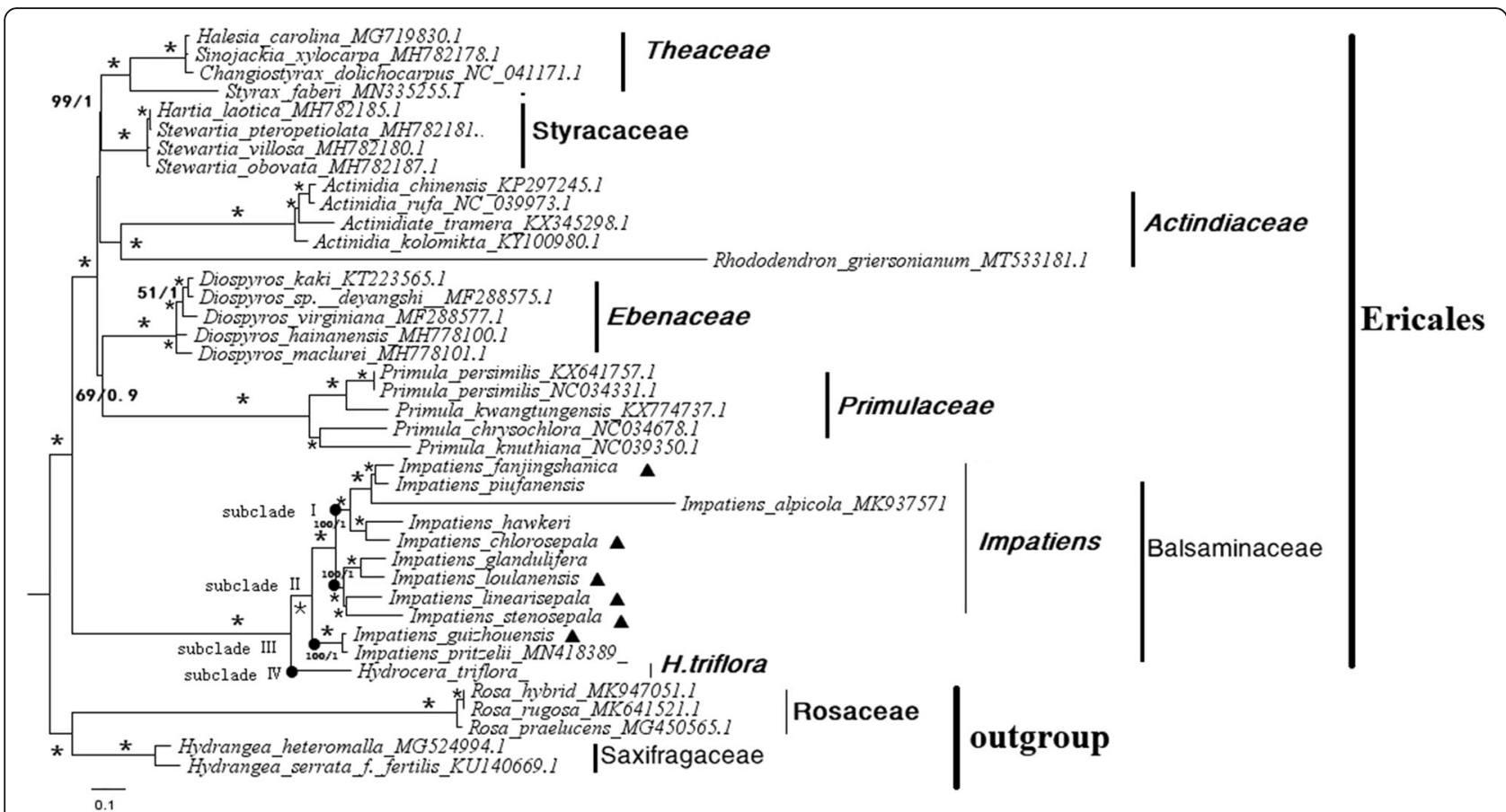

Fig. 8 Phylogenetic tree based on whole chloroplast genome sequences from 12 Balsaminaceae species and 28 other related species displaying maximum likelihood bootstrap support (MLBS) values and Bayesian posterior probabilities (PPs). The ML topology is shown with MLBS values/ Bayesian PPs given at each node. Asterisks indicate that PP $=1$ and MLBS $=100 \%$. Black dots indicate the four main lineages of Impatiens species. Black triangles indicate the chloroplast genomes of the six Impatiens species newly determined in this study

species exhibit a typical quadripartite structure consisting of two IR regions (LSC and SSC fragments) [32, 33]. The chloroplast genes of Balsaminaceae were similar in size (there was a maximum $1436 \mathrm{bp}$ difference in length between the Impatiens species) and composition (overall GC contents varied between 34.3 and 34.8\%). Among the plastomes, that of $H$. triflora was the largest (154, $189 \mathrm{bp})$. Compared with that of $H$. triflora, the plastomes of the Impatiens species were reduced in size by approximately $1387-2823 \mathrm{bp}$. In the most reduced plastome (151,538 bp) of I. fanjingshanica, contraction and expansion of IR boundaries were observed, suggesting that these processes are partly responsible for plastome downsizing in Balsaminaceae species. Potential trnG$U C C$ genes were annotated in all genomes of the Impatiens species but not in that of H. triflora. Converserly, the pbf1 gene was annotated only in I. glandulifera. Approximately 13 photosynthesis-related genes (ccsA, nadA, ndhD-I, orf188, psaC, rpl32, rps15, and trnL$U A G)$ were missing due to incorrect annotation in $I$. alpicola. The GC content of I. chlorosepala was found to be lower than that of the other species (Table 1). The GC content in the IR regions was much higher than that in the LSC and SSC regions in all Balsaminaceae species. The rRNA and tRNA genes had high GC contents (52$55 \%)$. Usually, a higher GC content indicated a more stable genome sequence. These data strongly showed that chloroplast genomes differ within the same family [33]. However, the basic structures and contents of the genomes were generally similar.

\section{IR expansion and contraction}

In most cases, gene gain or loss in chloroplast genomes is due to the contraction or expansion of genome regions. The presence of the pseudogene $y c f 1$ could be the result of such events. This was apparent in the plastomes of I. chlorosepala, I. guizhouensis, and I. loulanensis, where the IRs were much longer. Interestingly, the chloroplast LSC borders in I. linearisepala and I. guizhouensis were quite different from those in the other Balsaminaceae species, as the $n d h F$ gene extended into the IRs and SSC region. In I. guizhouensis and I. stenosepala, the rps19 gene extended into the IRs and LSC region. The LSC region in I. fanjingshanica was shorter than that in the other 11 chloroplast genomes.

Repetitive sequence and simple sequence repeat analyses Analysis of various chloroplast genomes showed that repetitive sequences were essential for inducing indels and substitutions [34]. These sequences were not only play an important role in the rearrangement and stabilization of the chloroplast genome sequence but also affect the copy number differences among species [35]. We identified a total of 234 repeats in Balsaminaceae, falling into 
four different repetitive categories (Supplementary Table S5). Among all species, the most common types corresponded to palindromic repeats, which occurred 114 times (49.59\%), followed by forward repeats (108 instances, 46.34\%). Complement repeats were identified only in I. guizhouensis and I. pritzelii. Reverse repeats were found only in I. chlorosepala, I. fanjingshanica, I. linearisepala, I. alpicola, and I. hawkeri.

SSRs have been recognized as a primary source of molecular markers because they have a high polymorphism rate and abundant variation at the species level. Moreover, SSRs are useful for detecting genetic diversity and polymorphisms at the population, intraspecific, and cultivar levels, as well as for distinguishing species [36, 37]. A total of 51-109 SSRs were identified, with an overall length ranging from 3 to $10 \mathrm{bp}$. Additionally, mononucleotide SSRs were detected in all Balsaminaceae species with the highest frequency, providing ample markers for phylogenetic analysis. The number of SSRs in H. triflora was lower than that in I. chlorosepala. Poly (A)/(T) SSRs are usually more common than other SSR repeat types, whereas poly $(\mathrm{C} / \mathrm{G})$ repeats are relatively rare. We identified only hexanucleotide SSRs (ATTGGG) in H. triflora and poly G SSRs in I. guizhouensis. We also identified SSR repeat units (TAAA/TTTA) unique to I. chlorosepala and H. triflora. Most chloroplast SSRs were observed in noncoding regions and were short mononucleotide tandem repeats, and they commonly showed intraspecific variation in repeat numbers [38]. Due to slippage of DNA strands, repeated loci, pairwise sequence divergence, and highly divergent regions were detected, indicating that the present findings will be useful for investigating genetic diversity levels and genomes presenting a high mutation rate.

\section{The utility of Plastomes in Phylogenomics and DNA barcoding}

Divergence hotspots are usually used as evidence for species authentication and to provide phylogenetic information. Moreover, the IR regions show lower sequence divergence than the SSC and LSC regions. The noncoding regions and coding regions are less similar in angiosperm chloroplast genomes than in other genomes [39]. The following genes, trnk-UUU-rps16, trnG-GCC, atpH-atpL, rpoB-petN, rps4$n d h J, a c c D-p s a l, n d h F, r p l 32-c c s A$, and $y c f 1$ were detected as the most divergent. Moreover, two regions (trnG-GCC and $y c f 1)$ showed high levels of variation both within all the Balsaminaceae species and within the newly sequenced species $(\pi>0.8 \%)$. In the newly sequenced species, noncoding regions, such as the psbK-psbI, trnT-GGU-psbD, ycf4-cemA, rpl36-rps8, rpoB-trnC-GCA, trnP-UGG-psaJ, trnT-UGUtrnL-UAA, trnK-UUU-rps16, and trnQ-UUG genes, possessed high variability and thus represented potential molecular marker.

\section{Phylogenomic validation}

Balsaminaceae is considered to be a taxonomically controversial and complex family at both the morphological and molecular levels owing to their similar morphology and wide distribution areas of its constituent species [40]. Various analyses of the whole chloroplast genome have revealed that it contains sufficient informative loci for resolving molecular evolution and phylogenetic relationships within families and genera. The first molecular phylogeny of Impatiens was published by Fujihashi et al. [41]. However, the limited taxon samples and using of a distant outgroup (Tropaeolum in Tropaeolaceae) resulted in limited resolution of the phylogenetic relationships within the family. Based on nuclear ribosomal ITS and $a t p B-r b c L$, phylogenetic studies of 111 Balsaminaceae species provided, new insights, such as Impatiens colonizing areas from Southwest China to the African continent in three separate diversification events [42]. Subsequently, based on plastid, combined plastid and nuclear or combined plastid and pollen data, Impatiens species were further analyzed [43]. Although these results have laid an important foundation for the identification and classification of Balsaminaceae species, all previous published data were based on relatively short sequences from material with obvious regional characteristics, and the numbers of nuclear/chloroplast genes were somewhat low [44], which limited phylogenetic conclusions. Therefore, the results were too conflicting to provide sufficient information for elucidating the phylogenetic and evolutionary relationships among Balsaminaceae species.

Phylogenetic reconstruction using ML and BI recovered Balsaminaceae sister to all other studied families of Ericales. Nodes received high support values $(\mathrm{PP}=1$, $\mathrm{BS}=100 \%$ ) (Fig. 8), and were highly congruent with those recovered in previous studies. Witihin Balsaminaceae, four major lineages were recovered in agreement with $\mathrm{Yu}$ [28], who proposed a new classification of $\mathrm{Im}$ patiens based on morphological characteristics and combined sequence data from three genetic regions, including nuclear ribosomal ITS and plastid $a t p B-r b c L$ and $\operatorname{trn} L-F$ molecular datasets. This classification divided Impatiens into two subgenera (Clavicarpa and Impatiens) and seven sections of the subgenus Impatiens [28]. I. stenosepala belongs to the Semeiocardium section, which is characterized by the lack of peduncle or only a very short peduncle, fusion of the lower lobes of the united lateral petals on each side, obconic capsules, and brick-shaped seeds [45]. Here, we found that I. stenosepala was sister to I. linearisepala and both are fourcarpellate. I. chlorosepala belongs to the Uniflorae section, which is characterized by short fusiform capsules and a lack of peduncles. I. loulanensis has lower funnelform sepals and petioles without basal glands [46]. 
Compared to those of other related Impatiens species, the genome structure of I. guizhouensis was more similar to that of $H$. triflora. According to the reconstructed phylogeny, the chloroplast genome structure of I. guizhouensis represented the ancestral state of the Balsaminaceae family.

The morphological features of $\mathrm{H}$. triflora were as follows: leaves alternate, linear-lanceolate, sessile, sepals 4, unequal length, stamens 5 , ovaries 5 , and ovules per locule 2-3 [47]. The characteristics of Impatiens were as follows: valgus lip with single leaves, spirally arranged, opposite or whorled, stalked or sessile, sepals 3, sparsely 5 , lateral sepals free or connate, entire or toothed, pistil composed of 4 or 5 carpels, ovary upper, compartments 4 or 5 , each with 2 to many anatropous ovules [46]. The morphology of I. guizhouensis was similar to that of $H$. triflora, despite I. guizhouensis belongs to the genus Impatiens, suggesting the retention of ancestral character states. Overall, using the complete chloroplast genome may be suitable for understanding the mechanisms of evolution and substantially increasing the power to discriminate species in evolutionary lineages [48-50].

\section{Conclusions}

Comparative analyses involving 12 Balsaminaceae plastomes provided important new insights into plastome structure and evolution. Within the karst regions inhabited by Impatiens species, plastomes showed highly similar basic structures, sizes, GC contents, and gene numbers, orders and functions. However, contraction or expansion of IRs, sequence divergence and mutational hotspots, and a number of duplicated genes in the IRs were detected. Our results revealed highly variable regions that can be used as potential markers for species identification and phylogenetic inference. Additionally, ML- and BI-based phylogenomic analysis of chloroplast genome sequences yielded more accurate phylogenetic relationships within the Balsaminaceae and might provide valuable genomic resources for systematic evolutionary analyses of the family. Therefore, wholechloroplast genomics is useful for species identification, taxonomic clarification, and genomic evolutionary analysis. Further research on the relationships within Balsaminaceae should incorporate morphology and genomewide analyses to enhance our understanding of evolution.

\section{Methods}

\section{Ethical statement}

No specific permits were required for the collection of specimens for this study. This research was carried out in compliance with the relevant laws of China.

\section{Materials and DNA extraction}

In total, 12 individuals of Balsaminaceae species were included (Supplementary Table S1). Prof. Haiquan Huang collected and identified all newly sequenced plants in the karst area of Guizhou, Yunnan and Guangxi, and data for an additional six species were downloaded from GenBank. All voucher specimens were deposited in the Plant Laboratory of Southwest Forestry University, Kunming, Yunnan, China (Table 3). Fresh leaves were collected and immediately stored in liquid nitrogen. We extracted genomic DNA by using the Tiangen DNA Reagent Extraction Kit (Tiangen Biotech, Beijing, China) [49]. Approximately $5-10 \mu \mathrm{g}$ of genomic DNA was checked using spectrophotometry, and DNA integrity was examined by electrophoresis on a $1.5 \%$ agarose gel [51].

\section{Illumina sequencing, assembly, and annotation}

Using an Illumina MiSeq sequencer (PE150 reads), libraries were constructed based on purified genomic DNA and sequenced. The quality of paired-end Illumina reads was assessed with FastQC, and Bowtie v2.2.6 software was used with the default settings to select

Table $\mathbf{3}$ List of basic information for the Impatiens specimens

\begin{tabular}{|c|c|c|c|c|}
\hline Specimen & Altitude & $\begin{array}{l}\text { Latitude and } \\
\text { Longitude }\end{array}$ & Location & $\begin{array}{l}\text { Voucher } \\
\text { Specimen }\end{array}$ \\
\hline 1. chlorosepala & $821 \mathrm{~m}$ & $\begin{array}{l}\text { N22 } 58^{\prime} 964^{\prime \prime} \\
\text { E106 } 75^{\prime} 696^{\prime \prime}\end{array}$ & Orchid Valley Park, Pingxiang City, Congzuo City, Guangxi Province, China & $\begin{array}{l}\text { SWFU- } \\
\text { IBLE20161008 }\end{array}$ \\
\hline $\begin{array}{l}\text { I. } \\
\text { fanjingshanica }\end{array}$ & $540 \mathrm{~m}$ & 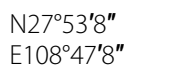 & Ganzitang, Tongren City, Guizhou Province, China & $\begin{array}{l}\text { SWFU- } \\
\text { IBFJS20171030 }\end{array}$ \\
\hline I. guizhouensis & $870 m$ & $\begin{array}{l}\text { N275ㄴㄷ' } \\
\text { E108 } 45^{\prime} 6^{\prime \prime}\end{array}$ & Fanjingshan Xiaochuanwan, Tongren City, Guizhou Province, China & $\begin{array}{l}\text { SWFU- } \\
\text { IBGZ20171030 }\end{array}$ \\
\hline I. linearisepala & $1320 \mathrm{~m}$ & $\begin{array}{l}\mathrm{N} 23^{\circ} 13^{\prime} 285^{\prime \prime} \\
\mathrm{E} 104^{\circ} 85^{\prime} 667^{\prime \prime}\end{array}$ & Malipo Laoshan Nature Reserve, Wenshan City, Yunnan Province, China & $\begin{array}{l}\text { SWFU- } \\
\text { IBXE20180928 }\end{array}$ \\
\hline 1. loulanensis & $1741 \mathrm{~m}$ & $\begin{array}{l}\mathrm{N} 26^{\circ} 10^{\prime} 249^{\prime \prime} \\
\mathrm{E} 104^{\circ} 35^{\prime} 593^{\prime \prime}\end{array}$ & $\begin{array}{l}\text { Luoduo Village, Yuni Township, Pan County, Liupanshui, Guizhou Province, } \\
\text { China }\end{array}$ & $\begin{array}{l}\text { SWFU- } \\
\text { IBLN20161013 }\end{array}$ \\
\hline I. stenosepala & $730 \mathrm{~m}$ & $\begin{array}{l}\mathrm{N} 27^{\circ} 51^{\prime} 55^{\prime \prime} \\
\mathrm{E} 108^{\circ} 45^{\prime} 33^{\prime \prime}\end{array}$ & Fanjing Mountain Erdaoguai, Tongren City, Guizhou Province, China & $\begin{array}{l}\text { SWFU- } \\
\text { IBZE20171030 }\end{array}$ \\
\hline
\end{tabular}


trimmed reads that corresponded to the plastid, using the plastome of I. piufanensis as a reference [50]. The Contigs were assembled using SPAdes 3.6.1. The assemblies were manually corrected using GetOrganelle version 1.6.2 with default settings [52]. Each assembled chloroplast genome was annotated with GeSeq and Dual Organellar Genome Annotator (DOGAM), and the start and stop codon positions were further searched by homologous gene identification $[53,54]$. In addition, the position of intron-exon junctions in the protein-coding genes, rRNAs, and tRNAs was confirmed with the BLASTN and tRNAscan v1.23 programs [55]. The genes were manually corrected when necessary and verified using Geneious R8.0.2 by realignment with references [56]. Physical circular chloroplast genome maps were generated by OGDrawV1.2 software [57]. Protein-coding genes were detected by comparison with the reference species I. glandulifera (GenBank MK358447) and I. piufanensis (GenBank MG162586). The GC content was calculated with Geneious R8.0.2.

\section{Repeat sequence and simple sequence repeat analyses}

The size and location of repeat sequences (forward, palindromic, reverse, and complement repeats) were identified by REPuter [58] with the following settings: sequence identity was $90 \%$, the Hamming distance was 3 , and the minimum repeat size was $30 \mathrm{bp}$. Online MISA software (http://pgrc.ipkgatersleben.de/misa/misa.html) was used to detect SSRs with minimum repeat number settings of $10,5,4,4,4$, and 4 for mononucleotides, dinucleotides, trinucleotides, tetranucleotides, pentanucleotides, and hexanucleotides, respectively [59].

\section{Codon usage analysis and genome alignment}

CodonW software was used to investigate the distribution of codon usage using the RSCU ratio [60]. To detect divergence hotspots, the online software MAFFT was used to align the whole chloroplast genomes [61]. The whole-genome alignment of Impatiens and other species was assessed by the mVISTA program in Shuffle-LAGA $\mathrm{N}$ mode [62]. DnaSP was used to calculate nucleotide divergence values using the sliding window method with a window length of $800 \mathrm{bp}$ and a $200 \mathrm{bp}$ step size [63]. Genome-wide alignment with the $H$. triflora chloroplast genome was performed using Mauve software and the MAFFT program [64].

\section{Phylogenetic analyses}

The chloroplast genomes from seven families belonging to the Ericales, including 12 Balsaminaceae species, six Primulaceae species, five Ebenaceae species, four Theaceae species, two Saxifragaceae species, and four Actinidiaceae species were analyzed. Saxifragaceae and Rosaceae species were selected as outgroups due to their closer distances from Ericales as well as ornamental and horticulture value (Supplementary Table S8). The aligned sequences were concatenated with MAFFT version 7.222 and default parameter settings [65]. ML trees were constructed using rapid bootstrapping (1000 replicates) and the search for the best-scoring ML tree option of RAxML v8.2.9 [66]. Based on the Akaike information criterion (AIC) in ModelTest-NG v0.1.6, the best-fitting substitution model $(\mathrm{GTR}+\mathrm{F}+\mathrm{I}+\mathrm{G} 4)$ was used for ML analyses [67]. The BI tree was generated in MrBayes version 3.2 [68]. The Markov chain Monte Carlo (MCMC) [69] consisted on one million generations with four independent heated chains with sampling after every 1000 generations [70], Burn-in was $10 \%$. The best-fitting substitution model $(\mathrm{TVM}+\mathrm{F}+\mathrm{I})$ was determined in jModelTest v.2.1.10. The FigTree ver 1.4.2 was used to visualize the output trees [71].

\section{Abbreviations}

Bl: Bayesian inference; bp: base pairs; ETS: External transcribed spacer; Gb: Gigabases; IGR: Intergenic region; IR: Inverted repeat; ITS: Internal transcribed spacer; LSC: Long single copy; LSR: Long sequence repeat; MCMC: Markov chain Monte Carlo; ML: Maximum likelihood; NCBI: National Center for Biotechnology Information; NGS: Next-generation sequencing; PCR: Polymerase chain reaction; PI: Parsimony informative; rRNA: ribosomal RNA; SSC: Short single copy; SSR: Simple sequence repeat; tRNA: transfer RNA

\section{Supplementary Information}

The online version contains supplementary material available at https://doi. org/10.1186/s12864-021-07807-8.

\section{Additional file 1: Table S1. Complete chloroplast genomes for 12 Balsaminaceae species. Table S2. Distribution of genes for 12 species in Balsaminaceae. Table S3. Genes with introns in the chloroplast genomes of newly sequenced Balsaminaceae species. Table S4. Codon content of amino acids and stop codons of Balsaminaceae species. Table S5. Comparison of long repeats among Balsaminaceae species. Table S6. Comparison of SSRs among 12 Balsaminaceae species. Table S7. The nucleotide variability $(\pi)$ values of Balsaminaceae species. Table S8. GenBank accession numbers of 40 species used in phylogenetic analysis.}

Additional file 2: Supplementary Figs. S1-6. Chloroplast genome structure of six Impatiens species (I. chlorosepala, I. fanjingshanica, I. guizhouensis, I. linearisepala, I. loulanensis, and I. stenosepala). Supplementary Figs. S7-12. Original pictures of six Impatiens species (I. chlorosepala, I. fanjingshanica, I. guizhouensis, I. linearisepala, I. loulanensis, and I. stenosepala).

\section{Acknowledgments}

We thank Dan Zong for teaching us how to use the software for the experiments. Our sincere thanks also go to the anonymous reviewers for their comments and suggestions.

\section{Authors' contributions}

C.L. designed the experiment and wrote the manuscript. C.L., W. H., Y.L. and X.L. contributed to the sampling. C.L., H.S. and H.Y. analyzed the data. C.L., B.Y., Q.W. and Y.W. performed the experiments. M.H. and H.H. proofread the manuscript. All authors have read and agreed to the published version of the manuscript.

\section{Funding}

This work was carried out with the support of the National Natural Science Foundation of China [32060364; 32060366; 31860230], Key Research and Development Plan Program of Yunnan Province [2018BB013], Young and Middle-aged Academic and Technical Leadership Training Project of Yunnan 
[2015HB046; 2018HB024], and Program for Innovative Research Team (in Science and Technology) at the University of Yunnan Province.

\section{Availability of data and materials}

All data generated or analyzed during this study are included in the published article, and the six newly sequenced complete chloroplast genomes were submitted to GenBank under accession numbers MW411293MW411298. The accession numbers corresponding to the additional datasets used and analyzed in this study can be found in Supplementary Table S8. These data were retrieved from the National Center for Biotechnology Information database.https://www.ncbi.nlm.nih.gov/nuccore/MW411293.1MW411298.

\section{Declarations}

\section{Ethics approval and consent to participate}

Not applicable. No specific permits were required for the collection of specimens for this study. This research was carried out in compliance with the relevant laws of China.

\section{Consent for publication}

Not applicable.

\section{Competing interests}

The authors declare that they have no competing interests.

\section{Author details}

${ }^{1}$ College of Landscape Architecture and Horticulture Sciences, Southwest Research Center for Engineering Technology of Landscape Architecture(State Forestry and Grassland Administration), Yunnan Engineering Research Center for Functional Flower Resources and Industrialization, Research and Development Center of Landscape Plants and Horticulture Flowers, Southwest Forestry University, Kunming, Yunnan 650224, China. ${ }^{2}$ Department of Landscape Architecture and Plant Science, University of Connecticut, Storrs, CT 06269, USA.

Received: 21 December 2020 Accepted: 14 June 2021

Published online: 24 July 2021

\section{References}

1. Liang H, Zhang Y, Deng J, Gao G, Ding C, Zhang L, et al. The complete chloroplast genome sequences of 14 Curcuma species: insights into genome evolution and phylogenetic relationships within Zingiberales. Front Genet. 2020;11:802. https://doi.org/10.3389/fgene.2020.00802.

2. Lee SR, Kim K, Lee BY, Lim CE. Complete chloroplast genomes of all six Hosta species occurring in Korea: molecular structures, comparative, and phylogenetic analyses. BMC Genomics. 2019;20(1):833. https://doi.org/10.11 86/s12864-019-6215-y.

3. Zhou T, Zhu H, Wang J. Complete chloroplast genome sequence determination of Rheum species and comparative chloroplast genomics for the members of Rumiceae. Plant Cell Rep. 2020;39(6):811-24. https://doi. org/10.1007/s00299-020-02532-0.

4. Han T, Li M, Li J, Lv H, Ren B, Chen J, et al. Comparison of chloroplast genomes of Gynura species: sequence variation, genome rearrangement and divergence studies. BMC Genomics. 2019;20(1):791. https://doi.org/10.11 86/s12864-019-6196-X.

5. Ren T, Yang Y, Zhou T, Liu ZL. Comparative plastid genomes of Primula species: sequence divergence and phylogenetic relationships. Int J Mol Sci. 2018:19(4):1050. https://doi.org/10.3390/ijms19041050.

6. Yang Z, Zhao T, Ma Q, Liang L, Wang G. Comparative genomics and phylogenetic analysis revealed the chloroplast genome variation and interspecific relationships of Corylus (Betulaceae) species. Front Plant Sci. 2018:9:927. https://doi.org/10.3389/fpls.2018.00927.

7. Li C, Zhao Y, Xu Z, Yang G, Peng J, Peng X. Initial characterization of the chloroplast genome of Vicia sepium, an important wild resource plant, and related inferences about its evolution. Front Genet. 2020;11:73. https://doi. org/10.3389/fgene.2020.00073.

8. Watson L, Bates P, Evans T, Unwin M, Estes J. Molecular phylogeny of subtribe Artemisiinae (Asteraceae), including Artemisia and its allied and segregate genera. BMC Evol Biol. 2002;2(1):17. https://doi.org/10.1186/14 71-2148-2-17.
9. Cheng Y, Zhang L, Qi J, Zhang L. Complete chloroplast genome sequence of Hibiscus cannabinus and comparative analysis of the Malvaceae Family. Front Genet. 2020;11:227. https://doi.org/10.3389/fgene.2020.00227.

10. Li DM, Zhao CY, Liu XF. Complete chloroplast genome sequences of Kaempferia Galanga and Kaempferia Elegans: molecular structures and comparative analysis. Molecules. 2019;24(3):474. https://doi.org/10.3390/ molecules24030474

11. Cho MS, Yang JY, Yang TJ, Kim SC. Evolutionary comparison of the chloroplast genome in the Woody Sonchus Alliance (Asteraceae) on the Canary Islands. Genes. 2019;10(3):217. https://doi.org/10.3390/genes10030217.

12. Grey-Wilson C. Impatiens in Papuasia. Studies in Balsaminaceae: I. Kew. Bull. 1980b;34:661-88.

13. Grey-Wilson C. A revision of Sumatran Impatiens. Studies in Balsaminaceae: VIII. Kew. Bull. 1989;44:67-105.

14. Janssens SB, Wilson SY, Yuan YM, Nagels A, Smets EF. Huysmans S. A total evidence approach using palynological characters to infer the complex evolutionary history of the Asian Impatiens (Balsaminaceae). Taxon 2012;61, 355-367, 2, DOl: https://doi.org/10.1002/tax.612007.

15. Janssens SB, Knox EB, Huysmans S, Smets EF, VFST M. Rapid radiation of Impatiens (Balsaminaceae) during Pliocene and Pleistocene: result of a global climate change. Mol Phylogenet Evol. 2009;52(3):806-24. https://doi. org/10.1016/j.ympev.2009.04.013.

16. Grey WC. Impatiens in Papuasia. Studies in Balsaminaceae: I. Kew. Bull. 1980; 34:661-88.

17. Cai $X Z$, Yi RY, Zhuang YH, Cong YY, Kuang RP, Liu KM. Seed coat micromorphology characteristics of Impatiens $L$ and its systematic significance. Acta Hort Sin. 2013;40:1337-48.

18. Jiang HF, Zhuang ZH, Hou BW, Shi BJ, Shu HJ, Chen L, Shi GX, Zhang WM Adverse effects of hydroalcoholic extracts and the major components in the stems of Impatiens balsamina L. on Caenorhabditis elegans. Evid Based Complementary Altern Med. 2017;2017(4245830):10. https://doi.org/10.11 55/2017/4245830.

19. Kim CS, Bae M, Oh J, Subedi L, Suh WS, Choi SZ. Anti-neurodegenerative biflavonoid glycosides from Impatiens balsamina. J Nat Prod. 2017;80(2): 471-8. https://doi.org/10.1021/acs.jnatprod.6b00981.

20. Lai HY, Cai MC. Effects of extended growth periods on subcellular distribution, chemical forms, and the translocation of cadmium in Impatiens walleriana. Int J Phytoremediation. 2016;18(3):228-34.

21. Ruchisansakun $S$, Niet T, Van Der T, Janssens SB, Triboun $P$, Jenjittikul T, et al. Phylogenetic analyses of molecular data and reconstruction of morphological character evolution in Asian Impatiens section Semeiocardium (Balsaminaceae). Syst Bot. 2015;40:1063-74.

22. Rahelivololona EM, Fischer E, Janssens SB, Razafimandimbison SG. Phylogeny, infrageneric classification and species delimitation in the Malagasy Impatiens (Balsaminaceae). PhytoKeys. 2018;110(110):51-67. https://doi.org/10.3897/phytokeys.110.28216.

23. Shajitha PP, Dhanesh NR, Ebin PJ, Joseph L, Devassy A, John R, et al. Molecular phylogeny of balsams (genus Impatiens) based on ITS regions of nuclear ribosomal DNA implies two colonization events in South India. J Appl Biol Biot. 2016:4:1-9.

24. Janssens SB, Geuten K, Yuan YM, Song Y, Kupfer P, Smets E. Phylogenetics of Impatiens and Hydrocera (Balsaminaceae) using chloroplast atpB-rbcL spacer sequences. Syst Bot. 2006;31(1):171-80. https://doi.org/10.1600/0363 64406775971796.

25. Zhang JG, Zhang LB. Impatiens shimianensis sp. Nov (Balsaminaceae): a new species from Sichuan, China, based on morphological and molecular evidence. Syst Bot. 2011;36:721-9.

26. Shajitha PP. A combined chloroplast atpB-rbcL and $t r n L-F$ phylogeny unveils the ancestry of balsams (Impatiens spp.) in the Western Ghats of India. 3 Biotech. 2016;6:258.

27. Yuan YM, Song Y, Geuten K, Rahelivololona E, Wohlhauser S, Fischer E, et al. Phylogeny and biogeography of Balsaminaceae inferred from ITS sequences. Taxon. 2004;53(2):391-403. https://doi.org/10.2307/4135617.

28. Yu SX, Janssens SB, Zhu XY, Lid, en M, Gao, TG, Wang W. Phylogeny of Impatiens (balsaminaceae): integrating molecular and morphological evidence into a new classification. Cladistics. 2016;32(2):179-97. https://doi. org/10.1111/cla.12119.

29. Luo Q, Wang TJ, Zhao LH. Impatiens menghuochengensis sp.nov. (Balsaminaceae) from Sichuan, China. Nor. J. Bot. 2015;32(6):839-43. 
30. Zhu ZL, Shi C, Cai NH, Ci XT, Peng JY, Duan AA, et al. The complete chloroplast genome of Yunnanopilia longistaminea (Opiliaceae), an endemic species in southwest China. Mitochondrial DNA Part B. 2019:4(2):3624-5.

31. Yan M, Zhao X, Zhou J, Huo Y, Din Y, Yuan Z. The complete chloroplast genomes of Punica granatum and a comparison with other species in Lythraceae. Int J Mol Sci. 2019;20(12):2886. https://doi.org/10.3390/ijms20122886.

32. Cheng H, Li J, Zhang H, Cai B, Gao Z, Qiao Y, et al. The complete chloroplast genome sequence of strawberry (Fragaria ananassa Duch.) and comparison with related species of Rosaceae. Peer J. 2017;5:e3919.

33. Luo C, Huang WL, Zhu JP, Feng ZX, Liu YL, Li Y, et al. The complete chloroplast genome of Impatien suliginosa Franch., an endemic species in Southwest China. Mitochondrial DNA Part B. 2019;4(2):3846-7.

34. Gu C, Tembrock LR, Zheng S, Wu Z. The complete chloroplast genome of Catha edulis: a comparative analysis of genome features with related species. Int J Mol Sci. 2018;19(2):525. https://doi.org/10.3390/ijms19020525.

35. Park M, Park H, Lee H, Lee BH, Lee J. The complete Plastome sequence of an Antarctic bryophyte Sanionia uncinata (Hedw.) Loeske. Int J Mol Sci. 2018; 19(3):709. https://doi.org/10.3390/ijms19030709.

36. Mader M, Pakull B, Blanc-Jolivet C, Paulini-Drewes M, Bouda ZH.N, Degen B, Small I, Kersten B. Complete chloroplast genome sequences of four Meliaceae species and comparative analyses. Int J Mol Sci 2018; 19, 701, 3, DOI: https://doi.org/10.3390/ijms19030701

37. Thiel T, Michalek W, Varshney R, Graner A. Exploiting EST databases for the development and characterization of gene-derived SSR-markers in barley (Hordeum vulgare L.). Theor Appl Genet. 2003;106:411-22.

38. Ebert D, Peakall R. Chloroplast simple sequence repeats (cpSSRs): technical resources and recommendations for expanding cPSSR discovery and applications to a wide array of plant species. Mol Ecol Resour. 2009;9(3): 673-90. https://doi.org/10.1111/j.1755-0998.2008.02319.x.

39. Li W, Zhang C, Guo X, Liu Q, Wang K. Complete chloroplast genome of Camellia japonica genome structures, comparative and phylogenetic analysis. PLoS ONE. 2019;14(5):e0216645.

40. Chen YL. Notulae de genere Impatiens L. flora Sinicae. Acta Phytotax. Sin. 1978;16:36-55

41. Fujihashi H, Akiyama S, Ohba H. Origin and relationships of the SinoHimalayan Impatiens (Balsaminaceae) based on molecular phylogenetic analysis, chromosome numbers and gross morphology. J Jap Bot. 2002;77: 284-95.

42. Yuan Y, Song Y, Geuten K, Rahelivololona E, Fischer E, Smets E, et al. Phylogeny and biogeography of Balsaminaceae inferred from ITS sequences. Taxon. 2004;53(2):391-403. https://doi.org/10.2307/4135617.

43. Cafa G, Baroncelli R, Elliso CA, Kurose D. Impatiens glandulifera (Himalayan balsam) chloroplast genome sequence as a promising target for populations studies. Peer.J. 2020;8:e8739. https://doi.org/10.7717/peerj.8739.

44. Tamboli AS, Dalavi JV, Patil SM, Yadav SR, Govindwar SP. Implication of ITS phylogeny for biogeographic analysis, and comparative study of morphological and molecular interspecies diversity in Indian Impatiens. Meta Gene. 2018;16:108-16. https://doi.org/10.1016/j.mgene.2018.02.005

45. Yu SX. Balsaminaceae of China. Beijing: Peking University Press; 2012.

46. Chen YL, Akiyama S, Ohba H. Balsaminaceae. In: Wu ZY, Paven PH, editors. Flora of China. Vol. 12. Beijing: Science Press; St. Louis: Missouri Botanical Garden Press; 2007. p. 75.

47. Chen YL. Balsaminaceae. In: Flora Reipublicae Popularis Sinica, Vol. 47. Beijing: Science Press; 2001. p. 1-243.

48. Dong W, Xu C, Wen J. Evolutionary directions of single nucleotide substitutions and structural mutations in the chloroplast genomes of the family Calycanthaceae. BMC Evol Biol. 2020;20:96.

49. Jin HP, Lee JJ. The complete plastid genome of Scopolia parviflora (Dunn.) Nakai(Solanaceae) Korean J. PI. Taxon. 2016;46(1):60-4.

50. Bankevich A, Nurk S, Antipov D, Gurevich AA, Dvorkin M, Kulikov AS, et al. SPAdes: a new genome assembly algorithm and its applications to singlecell sequencing. J CompBiol. 2012;19:455-77.

51. Doyle J, Doyle J. A rapid DNA isolation procedure for small quantities of leaf tissue. Phytochem Bull. 1987;19:11-5.

52. Jin JJ, Yu WB, Yang JB, Song Y, Yi TS, Li DZ. GetOrganelle: a fast and versatile toolkit for accurate de novo assembly of organelle genomes. Genome Biol. 2020;21:241. https://doi.org/10.1186/s13059-020-02154-5.

53. Tillich M, Lehwark $P$, Pellizzer $T$, Ulbricht-Jones ES, Fischer A, Bock R, et al. GeSeq-versatile and accurate annotation of organelle genomes. Nucleic Acids Res. 2017:4:W6-W11.
54. Wyman SK, Jansen RK, Boore JL. Automatic annotation of organellar genomes with DOGMA. Bioinformatics. 2004;20(17):3252-5. https://doi.org/1 0.1093/bioinformatics/bth352.

55. Peter S, Brooks AN, Lowe TM. The tRNAscan-SE, snoscan and snoGPS web servers for the detection of tRNAs and snoRNAs. Nucleic Acids Res. 2005;33: 686-9.

56. Kearse M, Moir R, Wilson A, Stones-Havas S, Cheung M, Sturrock S. Geneious basic: an integrated and extendable desktop software platform for the organization and analysis of sequence data. Bioinformatics. 2012;28(12): 1647-9. https://doi.org/10.1093/bioinformatics/bts199.

57. Lohse M, Drechsel O, Bock R. Organellar genome DRAW (OGDRAW): a too for the easy generation of high-quality custom graphical maps of plastid and mitochondrial genomes. Curr Genet. 2007;52(5-6):267-74. https://doi. org/10.1007/s00294-007-0161-y.

58. Kurtz S, Choudhuri JV, Ohlebusch E, Schleiermacher C, Stoye J, Giegerich R. REPuter: the manifold applications of repeat analysis on a genomic scale. Nucleic Acids Res. 2001;29(22):4633-42. https://doi.org/10.1093/nar/29.22.4633.

59. Beier S, Thiel T, Munch T, Scholz U, Mascher M. MISA-web: a web server for microsatellite prediction. Bioinformatics. 2017;33(16):2583-5. https://doi. org/10.1093/bioinformatics/btx198.

60. Sharp PM, Li WH. The codon adaptation index-a measure of directional synonymous codon usage bias, and its potential applications. Nucleic Acids Res. 1987;15(3):1281-95. https://doi.org/10.1093/nar/15.3.1281

61. Katoh K, Rozewicki J, Yamada KD. MAFFT online service: multiple sequence alignment, interactive sequence choice and visualization. Brief Bioinform. 2019:20(4):1160-6. https://doi.org/10.1093/bib/bbx108.

62. Frazer KA, Pachter L, Poliakov A, Rubin EM, Dubchak I. VISTA: computational tools for comparative genomics. Nucleic Acids Res. 2004;32(Web Server): W273-9. https://doi.org/10.1093/nar/gkh458.

63. Rozas J, Ferrer-Mata A, Sanchez-DelBarrio JC, Guirao-Rico S, Librado P, Ramos-Onsins SE, et al. DnaSP 6: DNA sequence polymorphism analysis of large data sets. Mol Biol Evol. 2017;34(12):3299-302. https://doi.org/10.1093/ molbev/msx248.

64. Darling AC, Mau B, Blattner FR, Perna NT. Mauve: multiple alignment of conserved genomic sequence with rearrangements. Genome Res. 2004; 14(7):1394-403. https://doi.org/10.1101/gr.2289704.

65. Katoh K, Standley DM. MAFFT multiple sequence alignment software version 7: improvements in performance and usability. Mol Biol Evol. 2013; 30(4):772-80. https://doi.org/10.1093/molbev/mst010.

66. Stamatakis A. RAxML version 8: a tool for phylogenetic analysis and postanalysis of large phylogenies. Bioinformatics. 2014;30(9):1312-3. https:// doi.org/10.1093/bioinformatics/btu033.

67. Darriba D, Posada D, Kozlov A, Stamatakis A, Morel B, Flouri T. ModelTestNG: a new and scalable tool for the selection of DNA and protein evolutionary models. Mol Biol Evol. 2020;37(1):291-4. https://doi.org/10.1093/molbev/ msz189.

68. Ronquist F, Teslenk M, van der Mark P, Ayres DL, Darling A, Hohna S, et al. MrBayes 3.2: efficient Bayesian phylogenetic inference and model choice across a large model space. Syst. Biol. 2012;61:539-42.

69. Hastings W. Monte Carlo sampling methods using Markov chains and their applications. Biometrika. 1970;57(1):97-109. https://doi.org/10.1093/biomet/ 57.1.97.

70. Darriba D, Taboada GL, Doallo R, Posada D. Europe PMC funders group. jModelTest 2: more models, new heuristics and high-performance computing. Nat Methods. 2015;9:6-9.

71. Ranbaut A (2014). FigTree ver. 1.4.2. http://tree.bio.ed.ac.uk/soft ware/fgtree. Accessed 13 February 2015.

\section{Publisher's Note}

Springer Nature remains neutral with regard to jurisdictional claims in published maps and institutional affiliations. 